\title{
ENERGY RECOVERY FROM AN INDUSTRIAL CLOTHES DRYER USING A CONDENSING HEAT EXCHANGER
}

\author{
by
}

Yousuf Farooq, B.Eng.

Ryerson University, 2004

\begin{abstract}
A Project Report
presented to Ryerson University

in partial fulfillment of the requirements for the degree of

Master of Engineering

in the Program of

Mechanical Engineering
\end{abstract}

Toronto, Ontario, Canada, 2005

Yousuf Farooq 2005 우 
UMI Number: EC53016

All rights reserved

INFORMATION TO USERS

The quality of this reproduction is dependent upon the quality of the copy submitted. Broken or indistinct print, colored or poor quality illustrations and photographs, print bleed-through, substandard margins, and improper alignment can adversely affect reproduction.

In the unlikely event that the author did not send a complete manuscript and there are missing pages, these will be noted. Also, if unauthorized copyright material had to be removed, a note will indicate the deletion.

\section{$\mathrm{UMI}^{\circ}$}

UMI Microform EC53016

Copyright 2008 by ProQuest LLC

All rights reserved. This microform edition is protected against unauthorized copying under Title 17, United States Code.

ProQuest LLC

789 East Eisenhower Parkway

P.O. Box 1346

Ann Arbor, MI 48106-1346 


\section{AUTHOR'S DECLARATION}

I hereby declare that I am the sole author of this project.

I authorize Ryerson University to lend this project to other institutions or individuals for the purpose of scholarly research.

I further authorize the Ryerson University to reproduce this project by photocopying or by other means, in total or in part, at the request of other institutions or individuals for the purpose of scholarly research. 


\section{ABSTRACT \\ Energy Recovery from an Industrial Clothes Dryer Using a Condensing Heat Exchanger \\ Master of Engineering 2005, Yousuf Farooq \\ School of Graduate Studies, Ryerson University}

The aim of this project was to design a condensing heat exchanger to recover waste heat from an industrial clothes dryer. Industrial cloth dryers are inefficient in their use of energy because almost all of the energy input in the dryer is wasted in the atmosphere, and thus there is great potential for heat recovery. This energy can be used to preheat the incoming cold water, and the conventional heater can then heat the water to a final temperature. The warm moist air from the dryer carries both sensible and latent heat, and in order to design this heat recovery condensing heat exchanger, the heat transfer by both mass and sensible heat has to be accounted for. The basis of this heat and mass transfer problem was the energy balance at the interface, and separate models for the calculation of latent and sensible heat transfer were used. The mass transfer coefficients were obtained from an analogy with heat transfer, and the unknown interface temperature was solved for iteratively. The data for this design was collected from a $20 \mathrm{~kW}$ dryer, and the heat recovery from that dryer was observed to be about $17.3 \%$. This heat recovery condensing heat exchanger efficiency can be enhanced by the addition of more coils to the heat exchanger. An improvement in the overall results can be expected if a practical study is done on the condensation heat exchanger for an industrial cloth dryer. 


\section{ACKNOWLEDGEMENTS}

It has been a privilege and an honor to work with Dr. David Naylor of Ryerson University and the author would like to thank Dr. David Naylor for his helpful assistance and guidance throughout the course of this work. The author would also like to thank his family for their complete support in the completion of this project. 


\section{TABLE OF CONTENTS}

PAGE

Author's Declaration........................................................................

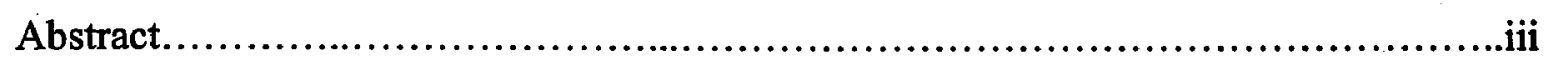

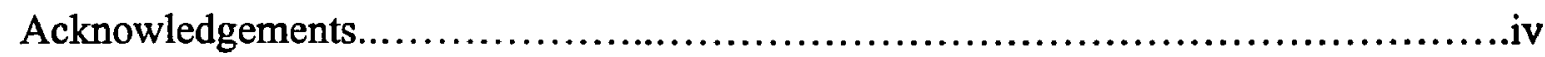

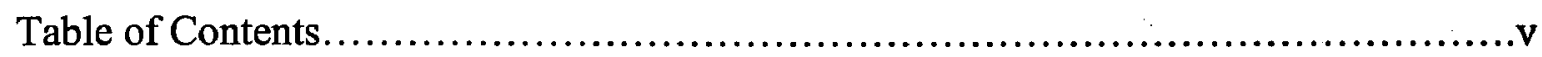

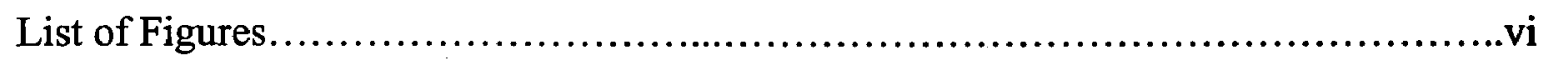

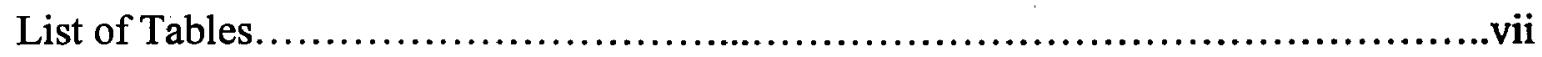

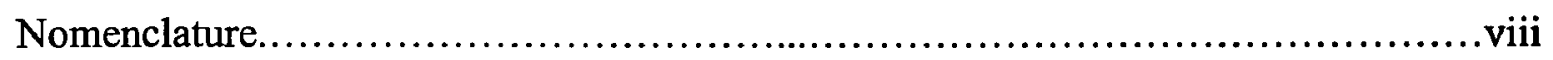

CHAPTER 1 - Introduction ..........................................................

CHAPTER 2 - Literature Review.................................................

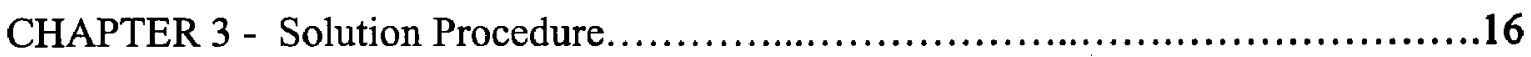

3.0 Introduction.......................................................... 16

3.1 Mass-transfer Resistance.................................................18

3.2 Sensible Heat Transfer Resistance......................................24

3.3 Condensation Heat Transfer............................................25

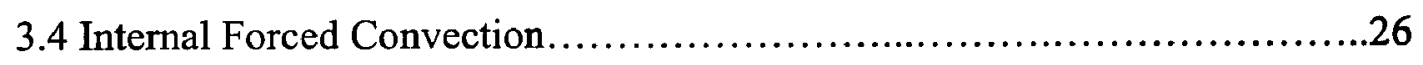

3.5 Overall heat-transfer Coefficient.......................................28

3.6 Condition after the Coil................................................ 31

3.7 Coils Pressure Drop Calculation........................................34

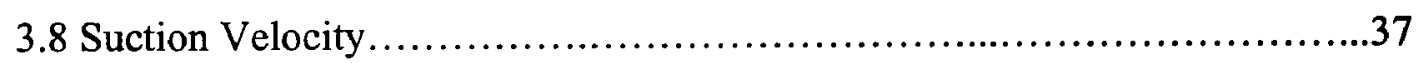

CHAPTER 4 - Results and Discussion.............................................38

APPENDIX A - Sample Mathematical Calculations.................................42

APPENDIX B - Sample EES Calculations and Results................................59

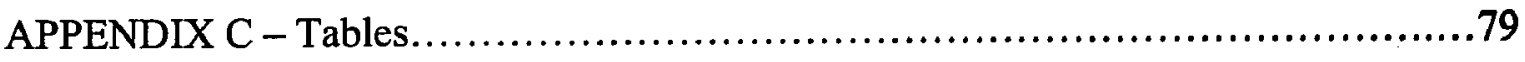

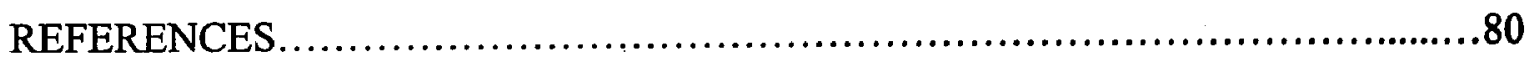




\section{LIST OF FIGURES}

FIGURE

1

2

3

4

5
DESCRIPTION

PAGE

Heat recovery condensing heat exchanger......................2

Side view and front view of the heat recovery condensing heat

exchanger................................................5

Equivalent thermal resistance diagram,.....................16

Friction factor for a staggered tube bank as a function of the

Reynolds number .34

Tube arrangement in a staggered tube bank.....................36 


\title{
LIST OF TABLES
}

\section{TABLE DESCRIPTION}

PAGE

1

\author{
Tabulated results. .
} .39 


\section{NOMENCLATURE}

\begin{tabular}{|c|c|}
\hline$A$ & Surface area \\
\hline$A_{c}$ & Cross sectional area \\
\hline$A_{o}$ & Outside cross sectional area \\
\hline$A_{i}$ & Inside cross sectional area \\
\hline$C p$ & Specific heat \\
\hline$D$ & Diameter \\
\hline$f$ & friction factor \\
\hline$F$ & Correction factor \\
\hline$g_{m}$ & Convective mass transfer conductance \\
\hline$h_{a 1}$ & Enthalpy of air at free stream \\
\hline$h_{a i}$ & Enthalpy of air at interface \\
\hline$h_{v 1}$ & Enthalpy of vapor at free stream \\
\hline$h_{v i}$ & Enthalpy of vapor at interface \\
\hline $\bar{h}_{\text {cond }}$ & Average convective heat transfer coefficient \\
\hline$h_{f g}$ & Latent heat of vaporization \\
\hline $\bar{h}_{i}$ & $\begin{array}{l}\text { Average convective heat transfer coefficient produced by internal forced } \\
\text { convection }\end{array}$ \\
\hline $\bar{h}_{\text {sen }}$ & $\begin{array}{l}\text { Average convective heat transfer coefficient produced by the sensible heat } \\
\text { transfer of air on the condensate film and outside surface of the pipe }\end{array}$ \\
\hline$K$ & Thermal conductivity \\
\hline$K_{\text {air }}$ & Thermal conductivity of air \\
\hline$M$ & Molecular weight \\
\hline$m_{a 1}$ & Mass fraction of air at free stream \\
\hline$m_{a i}$ & Mass fraction of air at interface \\
\hline$m_{v 1}$ & Mass fraction of water vapor at the free stream \\
\hline
\end{tabular}




\begin{tabular}{|c|c|}
\hline$m_{v i}$ & Mass fraction of water vapor interface \\
\hline$\dot{m}_{v}$ & Condensation rate \\
\hline$\dot{m}_{w}$ & Mass flow rate of the water inside the coil \\
\hline$N_{L}$ & Number of rows in heat exchanger \\
\hline $\bar{N} u$ & Average Nusselt number \\
\hline$P$ & Total pressure \\
\hline$P_{a 1}$ & Partial pressure of the air at the free stream \\
\hline$P_{a i}$ & Partial pressure of air at the interface \\
\hline $\operatorname{Pr}$ & Prandtl number \\
\hline$P_{\nu 1}$ & Partial pressure of water vapor at the free stream \\
\hline$P_{v i}$ & Partial pressure of water vapor at the interface \\
\hline$q$ & Heat transfer rate \\
\hline$q_{l}$ & Latent heat transfer rate \\
\hline$q_{o}$ & Heat transfer rate for pure vapor \\
\hline$Q$ & Volume flow rate \\
\hline$R$ & Universal gas constant \\
\hline$R_{\text {cond }}$ & Thermal resistance associated with the condensate film \\
\hline $\operatorname{Re}$ & Reynolds number \\
\hline$R_{i}$ & Thermal resistance associated with the convection inside the pipe \\
\hline$R_{\text {mass }}$ & Effective resistance associated with mass transfer of vapor to pipe wall \\
\hline$R_{o t}$ & Sum of mass and sensible resistances \\
\hline$R_{\text {sen }}$ & $\begin{array}{l}\text { Thermal resistance associated with sensible heat transfer of air to } \\
\text { condensate film }\end{array}$ \\
\hline$R_{\text {total }}$ & Total thermal resistance \\
\hline Sc & Schmidt number \\
\hline$\overline{S h}$ & Sherwood number \\
\hline$S_{L}$ & Longitudinal pitch \\
\hline
\end{tabular}




$\begin{array}{ll}S_{T} & \text { Transverse pitch } \\ T & \text { Temperature } \\ T_{1} & \text { Free stream temperature } \\ \bar{T}_{f} & \text { Film temperature } \\ \bar{T}_{i} & \text { Mean vapor film interface temperature } \\ \bar{T}_{s} & \text { Pipe surface temperature } \\ T_{w i} & \text { Water inlet temperature } \\ T_{w o} & \text { Water outlet temperature } \\ U & \text { Overall heat transfer coefficient } \\ U_{\text {max }} & \text { Maximum velocity } \\ v_{i} & \text { Fluid inlet specific volume } \\ v_{m} & \text { Fluid mean specific volume } \\ v_{o} & \text { Fluid outlet specific volume } \\ \bar{V} & \text { Free stream average velocity } \\ V_{i} & \text { Interfacial suction velocity } \\ w & \text { Specific humidity ratio } \\ W_{\infty} & \text { Free stream non-condensable gas mass fraction } \\ x & \text { Mole fraction }\end{array}$

\section{Greek Symbols}

$\begin{array}{ll}\phi_{1} & \text { Free relative humidity } \\ \phi_{o} & \text { Relative humidity at the flow core } \\ \Phi & \text { Correction factor for pressure drop calculation } \\ \varphi & \text { Dimensionless constant define by equation (3.20) } \\ v & \text { Kinematic viscosity of mixture } \\ \rho_{m} & \text { Density of mixture } \\ \rho_{a 1} & \text { Free stream air density }\end{array}$




$\begin{array}{ll}\rho_{a i} & \text { Air density at the interface } \\ \rho_{\nu 1} & \text { Free stream water vapor density } \\ \rho_{\nu i} & \text { Vapor density at the interface condition } \\ \rho_{w} & \text { Density of water } \\ \mu_{m} & \text { Viscosity of mixture } \\ \mu_{w} & \text { Viscosity of water } \\ \delta & \text { Mass transfer coefficient } \\ \kappa & \text { Molar mass transfer coefficient } \\ \mathrm{M}_{\nu} & \text { Mole weight to condensable vapor } \\ \lambda & \text { Latent heat } \\ \mathrm{P} & \text { Partial pressure }\end{array}$

\section{Subscripts}

$a$

$c$

$i$

$j$

w

$m$

$v$

1

2

$\infty$
Air

Condensate

Interface, first component of the mixture

Second component of the mixture

Water

Mixture

Vapor

Condition before coil

Condition after coil

Free stream 


\section{CHAPTER 1}

\section{Introduction}

The recovery of waste heat from an industrial clothes dryer is a feasible process. Almost all of the energy input in the dryer is wasted in the atmosphere, and this energy may be a good source to preheat the incoming cold water. The conventional heater can then heat the water to a final temperature.

A condensing heat exchanger for heat recovery from an industrial electric clothes dryer has been designed in this project. As shown in Figure 1, the hot exhaust air from the dryer is directed through a duct to a chamber, where horizontal copper pipes are staggered. The cold water flows inside the copper pipes and the hot exhaust air flows horizontally perpendicular to the outer surface of the copper pipes. A heat transfer process takes place between the hot exhaust air and the cold water. The pre-heated water from the heat recovery heat exchanger can be fed into a conventional heater or other heating equipment to heat the water to a desired temperature.

The temperature of the dryer exhaust (waste heat) and the required outlet temperature of the cold water are two key points for calculating the efficiency of the heat recovery system. As the temperature of the waste heat is lowered, the efficiency of the heat recovery system also decreases. The amount of moisture present in the dryer exhaust is another aspect that can contribute to the enhancement of the heat transfer rate. As the 
relative humidity of the dryer exhaust becomes higher, the latent heat available for recovery also increases.

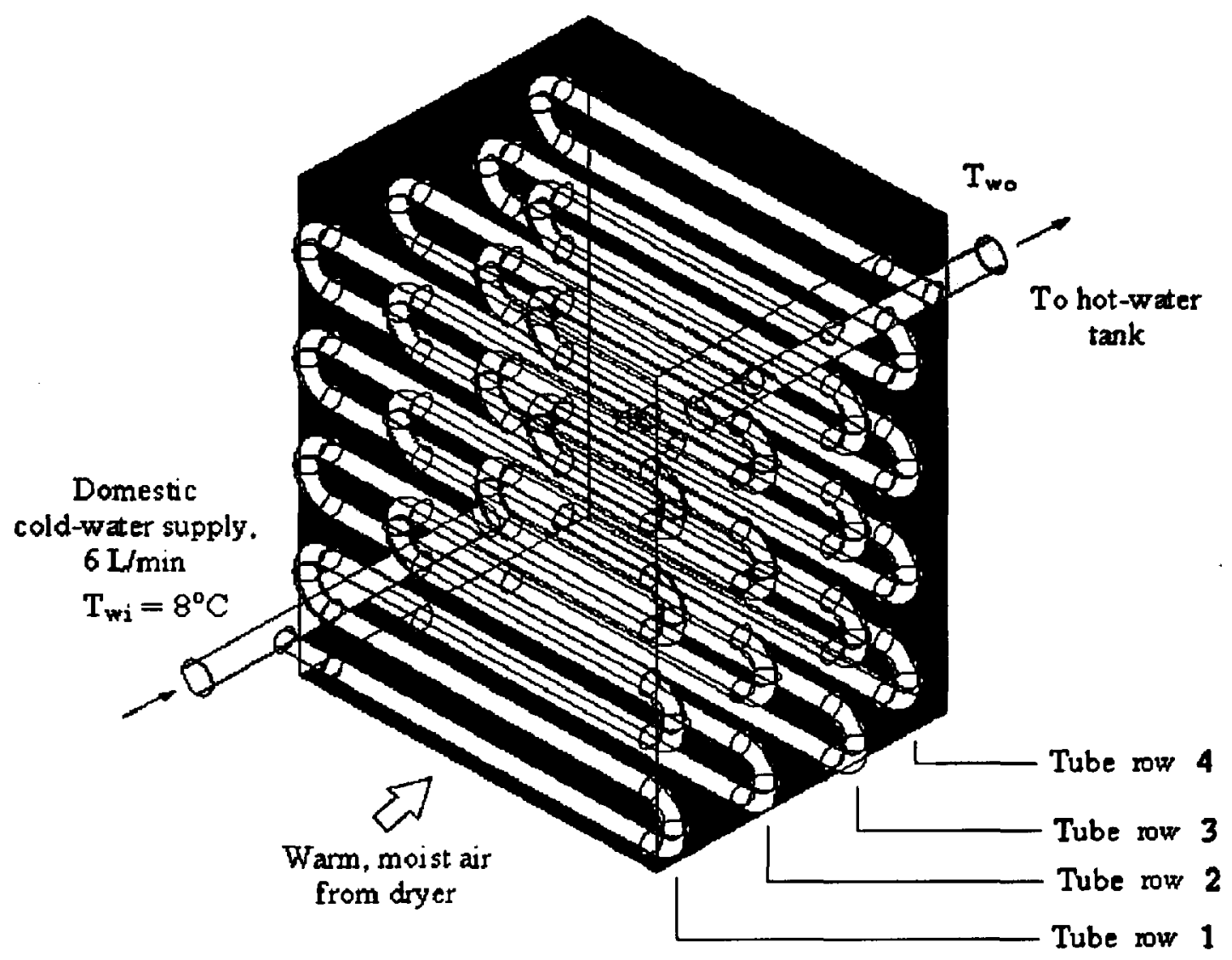

Figure 1. Heat recovery condensing heat exchanger.

Moist air from the dryer carries sensible heat of both air and water vapour, and latent heat of the water vapour. When the warm moist air first makes contact with the heat exchanger coil, the sensible heat transfer takes place from the air and the water vapour. If the coil temperature is below the dew point temperature of the moist air, water vapour condenses on the coil surface. The high humidity conditions ( $100 \%$ to $50 \%)$ have a higher proportion of moisture (higher portion of latent heat) and a corresponding lower 
portion of sensible heat. "For moderate vapour concentration the condensation heat transfer is of the same order as the convection heat transfer and cannot be neglected [1]." To design this condensing heat exchanger, the transfer of heat by both mass and sensible heat has to be accounted for. When the heat transfer process starts, the transport of heat is sensible transfer dominated, but after the steady state condition is achieved, the transport of heat is mass transfer dominated.

During the condensation of water vapour from the moist air, a liquid film forms on the surface of the coil and once the steady state condition is achieved, condensation occurs at the interface of the liquid film on the tube wall. As a result of the condensation process at the interface, there is a bulk velocity of the air towards the wall, as if there is suction at the interface. Only the water vapour condenses; therefore, the water concentration is reduced and suction is induced at the interface. For the case in which the air concentration is very high (moist air), as in this heat exchanger design, the suction effects are negligible.

The design of the heat recovery condensation heat exchanger for a clothes dryer is a complex problem, and it poses great challenges from the heat transfer efficiency point to the performance efficiency, applicability and ease of use in real life applications. For the purpose of this design, the data of typical and commercially available electric clothes dryers were collected. These data included the dryer's inlet and outlet conditions such as dryer load, dryer exhaust (dry bulb, wet bulb) temperatures, dryer humidity and exhaust gas flow rate. All of these parameters were recorded at the beginning, at the intermediate, 
and before the completion of the drying cycle. The average of the values of the above defined factors has been used as a parameter for the design of this heat recovery heat exchanger.

A major issue in the heat recovery applications of the clothes dryer is the presence of clothes lint in the dryer exhaust. The lint can accumulate on the tubes of the heat exchanger and it can create a resistance to the heat transfer and in the air flow. Cleaning of the lint from the heat exchanger tubes is not practically feasible. Therefore, an aircleaning filter can be used for the removal of lint from the dryer exhaust, and it can be placed after the dryer's primary filter for removing small particles of lint remaining, prior to allowing the warm and humid dryer exhaust air to pass into the heat exchanger. The removal of the condensate water from the bottom of the heat exchanger is another issue that can be resolved by providing a clean-out tray at the bottom of the heat exchanger. This is done in order to facilitate the condensate water from the heat exchanger bottom to drain.

Electrical clothes dryers are more popular in the industry than natural gas clothes dryers. Therefore, the design of this heat recovery dryer is based on an industrial electric clothes dryer that releases warm exhaust air at $60^{\circ} \mathrm{C}$ dry bulb temperature and $80 \%$ relative humidity. The flow rate of the exhaust air is about $0.13 \mathrm{~m}^{3} / \mathrm{s}$. The total pressure is assumed to be $100 \mathrm{kPa}$. The cold water flow inside the copper tubes has an inlet temperature of $8^{\circ} \mathrm{C}$ and a flow rate of $6 \mathrm{~L} / \mathrm{min}$. The length of the copper tube is 
1.7 meters for a single coil and four coils have been used. The total length of the copper tube is 6.42 meters. The schematic of the heat exchanger is shown in Figure 2.

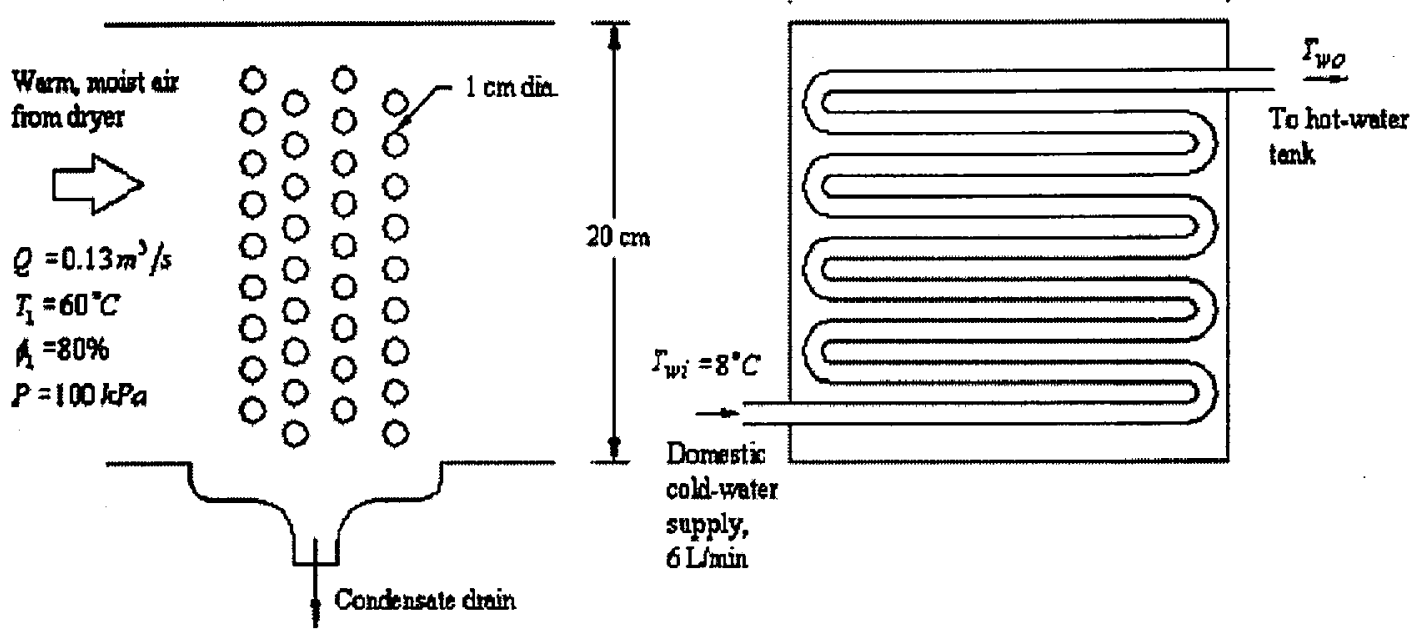

Figure 2. Side view and front view of the heat recovery condensing heat exchanger.

In this heat exchanger design, thin-walled bare copper tubes of $1.0 \mathrm{~cm}$ diameter have been used. The heat exchanger shown in Figure 2 has four staggered rows of tubes, and the tubes make nine passes in each row. The tubes are equally spaced in each row by a distance of $1.0 \mathrm{~cm}$, and, at both corners of the heat exchanger, two copper pipes of $2.5 \mathrm{~cm}$ diameter serve as headers for the incoming and outgoing water supply. Each row is connected to the inlet and outlet headers separately. This tube configuration is chosen to optimize the heat transfer rate because each row has the same temperature difference $\left(\Delta T=T_{1}-T_{w_{i}}\right)$ between the cold water inside the tube and free stream air; hence, more heat is transferred from the hot stream to the cold stream. Secondly, the wake shed by the first row of tubes produces a high level of free stream turbulence for the 
second row of tubes, thereby increasing the heat and mass transfer coefficients for the second row.

To understand the heat and mass transfer phenomenon during the condensation of moist air, various research papers and books related to the topic have been reviewed. Discussion from some major research papers on the issues related to mass and heat transfer have been included in the literature review section. This helps in understanding the theory, and provides a foundation for the design of the heat recovery condensing heat exchanger.

A detailed design procedure has been described in the solution procedure section, and a point-by-point iterative design method that estimates the sensible and latent heat transfer locally through the dry, humid exhaust condensate and tube wall to the cold water has been used. The iterations have been performed on a commercially available software called Engineering Equation Solver (EES) [2], which has a built-in function for thermodynamic properties. A sample hand calculation and the calculations from the software have been included in the appendix A. 


\section{CHAPTER 2}

\section{Literature Review}

The hot exhaust from the dryer is a mixture of air and water vapour, and it carries both the sensible heat of air and the latent heat of water vapour. Both air and water vapour lose sensible heat when they first contact the cooling coil. Water vapour is removed from the air only when the coil temperature is below the dew point temperature of the moist air. At the point where the coil starts to remove water vapour, the coil carries both the latent and sensible load. In the present problem, the water vapour is removed from the air with simultaneous mass and heat transfer between the air-stream and condensate wetted surface on the cooling coil. "Mass transfer by either molecular diffusion or convection is the transport of one component of a mixture relative to the motion of the mixture and is the result of a concentration gradient [3]."

During the condensation of vapour from the saturated air, the properties of air such as the heat transmission coefficient of the air film, the air flow rate and the heat capacity of the air stream - vary greatly as the water vapour is removed. The condensation of vapour depends upon the diffusion of the vapour molecules through the air; hence, the mass transmission, as well as the heat transmission coefficient, must be considered.

The writer reviews a research paper presented by J. W. Rose in 1979, in which

Rose [4] derived an approximate and theoretical based equation for condensation from a 
vapour gas mixture flowing parallel to a horizontal plate and normal to a horizontal tube. These approximate equations relate the mass flux of vapour to the condensing surface (condensation rate) to the free-stream and condensate surface conditions. "These equations may be used with suitable equations, giving the heat flux (or condensation rate) in terms of the temperature drop across the condensate film, to calculate the heat flux for given free-steam velocity, composition and temperature and condenser surface temperature. The equations are designed to be correct for the limiting case of zero and infinite condensation rate [4]."

Rose used the assumptions made by Sparrow, Minkowycz and Saddy [5]. According to those assumptions, it is allowed to take the interface velocity to be zero when the vapour-gas boundary layer is taken into consideration, and disregard the contribution to the heat flux in the condensate arising from the temperature gradient in the vapour-gas mixture, so that the energy equation for the vapour-gas mixture is no longer required. The thickening of the condensate film causes the condensation rate in the direction of flow to decrease. Rose compared his results with the numerical solution of Sparrow et al. [5], and the results were in good agreement.

For the case of a horizontal cylinder, Rose discussed the related case of heat transfer during flow normal to a cylinder and for a specified distribution of surface radial velocity. Rose compared his approximate equations with the experimental results obtained by Mills [6]. The calculations made by Rose show excellent agreement with Mills' observed values. 
Mills [6] reported the experimental data for the overall condensation rate for filmwise condensation from the steam-air mixture. The condensation rates were determined by condensate collections, and, for pure steam, the condensation rates were compared with the Nusselt type analyses of Fuji, Uehara and Oda [7] for constant heat flux condensation. For a steam-air mixture, Mills tried to correlate the normalized overall mass transfer conductance as a function of the mass transfer driving force. Mills' data were taken for the saturation temperatures of $307-339 \mathrm{~K}$, bulk temperature to wall temperature differences of 1.6-25.6 K, bulk air mass fraction 0-7.8 \% and oncoming vapour velocity of $0.28-0.98 \mathrm{~m} / \mathrm{s}[6]$.

For pure steam, Mills [6] reported that, because of the relatively large resistance of the condenser tube and inside film, the condensation occurs at nearly uniform heat flux around the tube. Mills compared his results for the pure steam case with uniform heat flux Nusselt type analysis and found that the heat transfer coefficients averaged 3.2 percent higher than the prediction of uniform heat flux Nusselt theory.

For the steam-air mixture, Mills [6] suggested that the reduction in heat transfer can be calculated from a correlation of the mass transfer conductance based on the asymptotic theory of Acrivos for boundary layers under strong suction.

Colburn and Drew [8] presented a theoretical and experimental study of the condensation of binary vapours which still stands as the most significant contribution to date in this field. Using the two-film theory, they postulated that, in addition to the liquid 
film on the plate, there would be adjacent to it a vapour film, and thus a vapour phase resistance to heat and mass transfer. Considering a saturated vapour of given temperature and composition under the condition of partial condensation, the liquid formed has a composition different from that of the bulk vapour. Assuming equilibrium at the interface, the vapour composition at that point is different from the bulk vapour composition, and thus the more volatile component will tend to back diffuse into the vapour [8].

A procedure of designing a cooler condenser in the presence of a non-condensable gas was presented by Colburn and Hougen [9], in which they mentioned that, for various reasons, no simple method of calculating the mean temperature differences based upon the terminal condition is applicable. Indeed, the true average temperature difference between the two fluid streams interchanging heat may be greater than the temperature difference at the either end of the condenser. The overall heat transfer coefficient varies from point to point in a cooler condenser. For calculating $U \Delta T$, Colburn and Hougen [9] used a trial and error method in which the rate of heat transfer through the gas film must be equal to that through the tube and the water film, that is:

$$
\underbrace{\bar{h}_{s}\left(T_{1}-T_{i}\right)}_{\text {sensible heat transfer }}+\underbrace{\kappa \mathrm{M}_{v} \lambda\left(\mathrm{P}_{v}-\mathrm{P}_{c}\right)}_{\text {latent }}=\underbrace{\bar{h}_{i}\left(\bar{T}_{i}-T_{w}\right)}_{\text {transfer }}=U \Delta T
$$

The solution of the above equation requires knowledge of the temperature at the interface between the condensate and gas phase, $\bar{T}_{i}$, and the corresponding vapour pressure of the condensate $P_{c}$. Various values are chosen until the desired equality is obtained, thus giving the value of $U \Delta T$ at the gas temperature selected [9]. 
Sparrow et al. [5] analytically explored the effect of non-condensable gas on condensation in a forced convection laminar boundary layer flow. In their paper, the solutions of the differential equations were found both numerically and by an integral method. For the steam-air system, the heat transfer, with and without the noncondensable gas, was compared for a wide range of conditions. They also examined the effect of the interfacial resistance, that is, a temperature jump at the liquid vapour interface.

The results in the work by Sparrow et al. [5] show that at any fixed temperature difference and fixed free stream temperature level, the heat transfer decreases monotonically as the mass fraction of non-condensable gas increases. The presence of non-condensable gas is more strongly manifested when the condensation takes place at sub-atmospheric pressure. At higher free stream temperature levels and at the lower mass fractions, the heat-transfer ratio $q / q o$ is insensitive to the temperature difference $\left(T_{\infty}-\bar{T}_{S}\right)$. When free stream temperature $T_{\infty}$ decreases, and free stream noncondensable gas mass fraction $W_{\infty}$ increases, the heat-transfer ratio becomes more sensitive to the temperature difference, decreasing as $\left(T_{\infty}-\bar{T}_{S}\right)$ increases.

"The decrease in the heat transfer rate can be attributed to the build-up of the noncondensable gas at the interface. The effect of such build-up is to lower the corresponding partial pressure of the vapour, which in turn lowers the interface temperature $\bar{T}_{i}$ at which the condensation occurs (the interface is at a saturation state). In 
this way, the thermal driving force $\left(\bar{T}_{i}-T_{w}\right)$ is lowered, thereby decreasing the heat transfer rate [5]."

Therekhov et al. [10], in their paper regarding heat and mass transfer in the condensation of water vapour from moist air, presented a computational model that was based on the solution of integral relations of boundary-layer energy and diffusion using the analogy of mass and heat transfer processes. The problem was solved using integral transport equations and the similarity of mass and heat transfer processes. In this method, Therekhov et al. disregarded the effect of the condensate forming on the surface, considering its thermal resistance to be negligibly small. "This assumption is justified because in the majority of the experiments conducted on the heat transfer of moist air in channels, a dropwise regime of condensation was observed. Drops forming on the cooled surface are periodically removed by the flowing air stream [10]."

Therekhov et al. performed calculations for a wide range of parameters in the flow core $\left(T_{1}=10\right.$ to $75^{\circ} \mathrm{C}, \phi_{\mathrm{o}}=0-100 \%, P=1 \times 10^{4}$ to $\left.1 \times 10^{6} \mathrm{~Pa}\right)$ and on the wall, $\bar{T}_{s}=-20$ to $50^{\circ} \mathrm{C}$. The thermo-physical properties were determined from the parameters of the wall, and the mixture enthalpy and the heat of phase transition were taken from the tabulated data and the Lewis number as a function of the vapour concentration.

The calculations performed by Therekhov et al. [10], for both laminar and turbulent regimes of the flow, showed that the relative humidity had a substantial effect on the temperatures at which maximum vapour condensation is attained. At the same 
time, the pressure of the gas-vapour mixture had a very slight effect on the wall temperature. Results of the calculation of the heat and mass fluxes on the wall for turbulent moist-air flow along an isothermal surface, and for a variation in relative humidity, showed that an increase in relative humidity in the flow core, $\phi_{0}$, leads to a substantial increase in the heat and mass fluxes. Thus, the intensification of the heat transfer in saturated air attains practically one order of magnitude relative to dry air flow.

Jia, L. et al. [1] had experimentally investigated the condensation heat transfer of wet flue gas. In this paper, Jia et al. noticed that the condensation heat transfer on the wet flue gas was different from that of pure vapour or the case with the presence of a small amount of non-condensable gas. Since the partial pressure of the water vapour in the wet flue gas was small, the resistance to the mass transfer was large and the condensation of the vapour was difficult. The heat transfer was influenced by the water vapour concentration in the gas mixture. In the experimental range (temperature range $25-80^{\circ} \mathrm{C}$ and water vapour concentration $20-30 \%$ ), the heat transfer coefficient was twice as great as the single-phase convection heat transfer.

Jia et al. [1] had concluded that for a very small amount of vapour $(10-20 \%)$, the contribution of condensation is not strong; therefore, heat transfer can be treated as a single-phase convection. For moderate vapour concentration, the condensation heat transfer is of the same order as the convection heat transfer and cannot be neglected. In the experimental investigation, when cold water was used to cool wet flue gas, the contribution of condensation heat transfer was about 3 to 4 times that of convection heat 
transfer. When the water vapour fraction is high, that is over $80 \%$, the convection heat transfer can be neglected.

From the above discussion of various research papers, it is evident that a moderate amount of concentration of water vapour in the air gives rise to a heat transfer coefficient. On the other hand, the calculation of heat transfer coefficient in the case of moist-air (mixture of water vapour and air) is not straightforward. The overall heat transfer coefficient varies from point to point in a condensing heat exchanger and it is high where the vapour concentration is high and low where most of the vapour has been removed. The mean temperature difference based on the terminal conditions can not be a true average temperature difference between the two fluid streams interchanging heat. Hence, calculating the average heat transfer coefficient by using the simple mean temperature difference (LMTD) is not a correct method.

Recently, Naylor and Oosthuizen [11] proposed a method for designing a condensing heat exchanger for recovering energy from an industrial electric clothes dryer. In a chapter published in the "Heat Transfer Calculations 2005," Naylor and Oosthuizen [11] proposed a point by point iterative method for calculating the value of $U \Delta T$. In that method, the heat transferred was equated locally through the condensate, the wall and the cooling-water to the sum of the latent heat of the condensate due to the vapour transferred by diffusion, while the sensible heat transfer from the air to the condensate film was ignored. The unknown interface temperature and corresponding pressure at the condensate-vapour interface were estimated by an iterative procedure in 
which various values for the temperature were chosen until convergence was achieved, and that selected temperature provided instantaneous values of $U \Delta T$. The coefficient of mass transfer by condensing vapour was estimated on the basis of the heat and mass transfer analogy. In this project, the same approach has been used and the component of sensible heat transfer has been included. 


\section{CHAPTER 3 \\ Solution Procedure}

\section{0 Introduction}

The heat transfer process from the hot exhaust air of the dryer to the water flowing inside the pipe has four heat transfer modes: mass transfer of vapour to the condensate surface, sensible (convection) heat transfer to the condensate film, conduction heat transfer from condensate film to the tube wall, and convection heat transfer from the tube wall to the water flowing inside the tube. To calculate the total heat transfer rate, a thermal resistance method has been used. The equivalent thermal resistance diagram shown in Figure 3 has four resistances: the thermal resistance associated with the convection inside the pipe $R_{i}$, the thermal resistance associated with the condensate film $R_{\text {cond }}$, the effective resistance associated with the mass transfer of vapour to pipe wall $R_{\text {mass }}$, and the thermal resistance associated with the sensible heat transfer of the air to the condensate film $R_{\text {sen }}$. The thermal resistance across the pipe wall is neglected. It should be noted that $R_{\text {mass }}$ is not a traditional thermal resistance but it should be treated as such for the purpose of this iterative method.

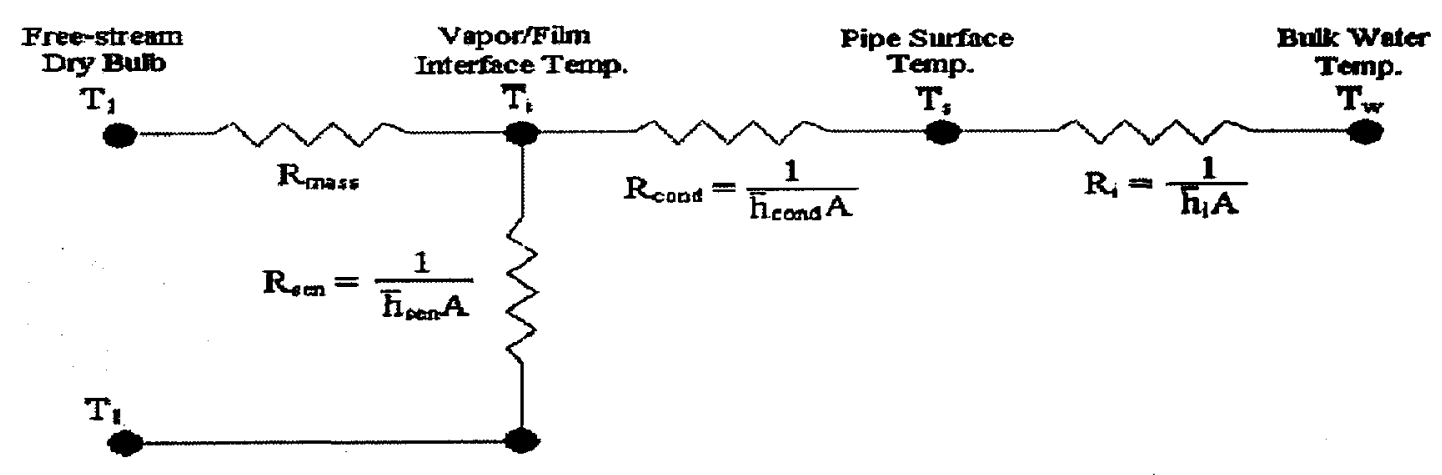

Figure 3. Equivalent thermal resistance diagram. 
- The total thermal resistance $R_{\text {total }}$ for the circuit will be the sum of the individual resistances. For a thin walled pipe, it is assumed that $A_{0} \approx A_{i}$, then:

$$
R_{\text {total }}=\left(\frac{1}{R_{\text {mass }}}+\frac{1}{R_{\text {sen }}}\right)^{-1}+R_{\text {cond }}+R_{i}
$$

Where each individual resistance can be expressed as:

$$
\begin{array}{ll}
R_{\text {mass }}=\frac{\left(T_{1}-\bar{T}_{i}\right)}{q_{l}}, & R_{\text {sen }}=\frac{1}{\bar{h}_{\text {sen }} A} \\
R_{\text {cond }}=\frac{1}{\bar{h}_{\text {cond }} A}, & R_{i}=\frac{1}{\bar{h}_{i} A}
\end{array}
$$

Where $\bar{h}_{\text {sen }}, \bar{h}_{\text {cond }}$ and $\bar{h}_{i}$ are the average convective heat transfer coefficients produced by the sensible heat transfer of air on the condensate film and outside surface of the pipe, condensation on the outside of the pipe, and internal forced convection on the inside of the pipe, respectively.

The overall heat transfer coefficient, $U$, can be expressed as:

$$
\begin{aligned}
& U A=R_{\text {total }}^{-1}=\left(R_{\text {ot }}+R_{\text {cond }}+R_{i}\right)^{-1} \\
& U=\left(A R_{\text {ot }}+\frac{1}{\bar{h}_{\text {cond }}}+\frac{1}{\bar{h}_{i}}\right)^{-1}
\end{aligned}
$$

Where

$$
R_{o t}=\left(\frac{1}{R_{\text {mass }}}+\frac{1}{R_{\text {sen }}}\right)^{-1}
$$




\subsection{Mass-transfer Resistance}

To initiate the iterative solution procedure, the mass transfer resistance will be calculated first. In this heat recovery process, water vapour will be removed from air with simultaneous heat and mass transfer. This combined heat and mass transfer problem can be calculated by using Chilton-Colburn analogy with Hilpert's empirical correlation for forced convection over a cylinder [6] [12].

In the case of external flow, when mass transfer occurs at the convective surface, the Nusselt number and Sherwood number are defined as follows:

$$
\begin{aligned}
& \bar{N} u=C \operatorname{Re}_{D}^{m} \operatorname{Pr}^{1 / 3} \\
& \overline{S h}=C \operatorname{Re}_{D}^{m} \operatorname{Pr}^{1 / 3}
\end{aligned}
$$

Where Pr is the Prandtl number and $S c$ is the Schmidt number.

The interfacial water vapour density and the interfacial temperature are unknown. To evaluate the air and mass transfer properties, a value is estimated for the condensate interfacial mean temperature, $\bar{T}_{i}$. This temperature is a "guess" value to start the iteration procedure and this value will be corrected as the solution proceeds. At this assumed interfacial temperature, the density of the air and water vapour at the interface condition can now be calculated. The interface vapour pressure, $P_{v i}$, corresponding to the water 
saturation pressure at the assumed interface temperature, $\bar{T}_{i}$, can be determined from the steam table.

The vapour density at the interface condition can be calculated by using the ideal gas law:

$$
\rho_{v i}=\frac{P_{v i} M_{v}}{R \bar{T}_{i}}
$$

To calculate the air density at the interface, a similar procedure can be used:

$$
\rho_{a i}=\frac{\left(P-P_{v i}\right) M_{a}}{R \bar{T}_{i}}=\frac{P_{a i} M_{a}}{R \bar{T}_{i}}
$$

The relative humidity at the free stream condition is $\phi_{1}$, the free stream temperature is $T_{1}$ and the vapour saturation pressure at this temperature is $P_{\text {sat }, 1}$. At the free stream condition, the partial pressure of water vapour is:

$$
P_{v 1}=\phi_{1} P_{s a t, 1}
$$

The free stream water vapour density can be calculated by using the ideal gas law:

$$
\rho_{\nu 1}=\frac{P_{v 1} M_{\nu}}{R \bar{T}_{1}}
$$


Similarly, ideal gas law can be used to calculate the free stream air density:

$\rho_{a 1}=\frac{\left(P-P_{\nu 1}\right) M_{a}}{R \bar{T}_{1}}=\frac{P_{a 1} M_{a}}{R \bar{T}_{1}}$

Now, the mean density of the mixture can be calculated as follows:

$\rho_{m}=\frac{\left(\rho_{v i}+\rho_{a i}\right)+\left(\rho_{v 1}+\rho_{a 1}\right)}{2}$

From the above interface density values, the interface mass fraction of water vapour can be calculated as follows:

$$
m_{i}=\frac{\rho_{v i}}{\rho_{v i}+\rho_{a i}}
$$

Similarly, the mass fraction of water vapour at the free stream can be calculated as follows:

$$
m_{1}=\frac{\rho_{v 1}}{\rho_{v 1}+\rho_{a 1}}
$$

The approximate film temperature is, $\bar{T}_{f}=\frac{T_{1}+\bar{T}_{i}}{2}$ and the air and mass transfer properties are calculated at this film temperature.

The diffusion coefficient $\delta$, can be calculated by the relationship proposed by Frank and David [3] as follows:

$$
\delta=0.26 \times 10^{-6}\left(\frac{\bar{T}_{f}}{298}\right)^{3 / 2}
$$


The mixture viscosity, $\mu_{m}$, has been evaluated by using Wilke's method [13]. A general equation for mixture viscosity as a function of molecular weights and viscosities of the pure components of the mixture was developed by Wilke [13]. The equation is in close agreement with the experimental data, which are believed sufficiently accurate for many purposes. Rose [4] recommended the Wilke method to calculate the mixture viscosity.

The Wilke equation is as follows:

$$
\mu_{m}=\frac{\mu_{1}}{1+\left(x_{1} / x_{2}\right) \varphi_{12}+\left(x_{2} / x_{1}\right) \varphi_{13}+\ldots}+\frac{\mu_{2}}{1+\left(x_{1} / x_{2}\right) \varphi_{21}+\left(x_{3} / x_{2}\right) \varphi_{23}+\ldots}+\ldots
$$

This above equation can be written in the general form:

$$
\mu_{m}=\sum_{i=1}^{n} \frac{\mu_{i}}{1+\frac{1}{x_{i}} \sum_{\substack{j=1 \\ j \neq i}}^{j=n} x_{j} \varphi_{i j}}
$$

Where $\varphi_{i j}$ is defined as follows:

$$
\varphi_{i j}=\frac{\left[1+\left(\mu_{i} / \mu_{j}\right)^{1 / 2}\left(M_{j} / M_{i}\right)^{1 / 4}\right]^{2}}{(4 / \sqrt{2})\left[1+\left(M_{i} / M_{j}\right)^{1 / 2}\right.}
$$

The kinematic viscosity of the mixture can be calculated as follows:

$$
v=\frac{\mu_{m}}{\rho_{m}}
$$


Where the Schmidt number is given by:

$$
S c=\frac{\nu}{\delta}
$$

From the given values of exhaust gas volume flow rate $Q\left(\mathrm{~m}^{3} / \mathrm{s}\right)$, and the duct cross

sectional area of the $A_{c}\left(\mathrm{~m}^{2}\right)$, the velocity of the exhaust gas can be calculated as:

$$
\bar{V}=\frac{Q}{A_{c}}
$$

The Reynolds number for the exhaust gas can be calculated as follows:

$$
\operatorname{Re}_{D}=\frac{\rho_{m} \bar{V} D}{\mu_{m}}
$$

Using the above mentioned Chilton-Colburn analogy, the Sherwood number can be calculated as follows:

$$
\overline{S h}=C \operatorname{Re}_{D}^{m} S c^{1 / 3}
$$

Hilpert's correlation constants $\mathrm{C}$ and $\mathrm{m}$ are tabulated in the Appendix $\mathrm{C}$.

From the above calculated values of Sherwood number, the convective mass transfer conductance $g_{m}$ can be calculated as follows:

$$
g_{m}=\frac{\rho_{m} \overline{S h} \delta}{D}
$$

The condensation rate, which is equal to mass transfer rate, can be calculated as follows:

$$
\dot{m}_{v}=g_{m} A\left(m_{v 1}-m_{v i}\right)
$$

The total pipe surface area is $A=\pi D L$ 
The latent heat transfer rate required to condense vapour at this rate can be calculated as follows:

$q_{l}=\dot{m}_{v} h_{f g}$

Where $h_{f g}$, the enthalpy of vaporization of water at interface temperature $\bar{T}_{i}$, can be obtained from the steam table.

Finally, the effective thermal resistance due to mass transfer can be calculated as follows:

$R_{\text {mass }}=\frac{\left(T_{1}-\bar{T}_{i}\right)}{q_{l}}$ 


\subsection{Sensible Heat Transfer Resistance}

The mixture of air and water vapour loses sensible heat when it first contacts the cooling coil. To calculate the sensible heat transfer coefficient, the Hilpert correlation has been used. From the point of view of engineering calculations, the empirical correlation proposed by Hilpert is widely used for gas flow over cylinders [11][12][14]. The Hilpert correlation is given as follows:

$\bar{N} u=C \operatorname{Re}_{D}^{m} \operatorname{Pr}^{1 / 3}$

Hilpert's correlation constants $C$ and $m$ are tabulated in the Appendix C1.

For air, the Prandtl number $\operatorname{Pr}$ and thermal conductivity $K_{\text {air }}$ are evaluated at the film temperature $\bar{T}_{f}=\frac{T_{1}+\bar{T}_{i}}{2}$, and the Reynolds number is given by

$\operatorname{Re}_{D}=\frac{\rho_{m} \bar{V} D}{\mu_{m}}$

The sensible heat transfer coefficient is as follows:

$\bar{h}_{\text {sen }}=\bar{N} u \frac{K_{\text {air }}}{D}$

The sensible heat transfer resistance is given by:

$R_{\text {sen }}=\frac{1}{\bar{h}_{\text {sen }} A}$

The total mass and sensible heat transfer resistance can be calculated as follows:

$R_{o t}=\left(\frac{1}{R_{\text {mass }}}+\frac{1}{R_{\text {sen }}}\right)^{-1}$ 


\subsection{Condensation Heat Transfer}

The condensation heat transfer coefficient for the outer surface of the pipes can be calculated by using an equation for laminar film condensation on the outer surface of a horizontal tube bank [11][14]. The average Nusselt number for the case of a vertically arranged horizontal tube bank that has $n$ tubes with a diameter $D$ is:

$$
\bar{N} u_{\text {cond }}=\frac{\bar{h}_{\text {cond }}(n D)}{K_{l}}=0.729\left[\frac{g h_{f g} \rho_{l}\left(\rho_{l}-\rho_{v}\right)(n D)^{3}}{\mu_{l} K_{l}\left(\overline{T_{i}}-\overline{T_{s}}\right)}\right]^{1 / 4}
$$

In the above equation, the liquid film properties are determined at condensate mean film temperature, which is $\left(\bar{T}_{s}+\bar{T}_{i}\right) / 2$. The temperature difference between the pipe surface temperature $\bar{T}_{s}$, and the mean vapor film temperature (interface temperature) $\bar{T}_{i}$, is unknown. It is important to make an initial guess for the temperature drop between the pipe surface temperature and the vapour film temperature, $\bar{T}_{i}-\bar{T}_{s}$, to begin the iteration procedure. As the iteration process proceeds, these assumed values will be corrected to the temperature difference $\bar{T}_{i}-\bar{T}_{s}$. 


\subsection{Internal Forced Convection}

Internal forced convection occurs when the fluid goes into the tube at a uniform temperature that is less than that of the tube surface temperature. Internal flow is the one in which flow is confined by a surface such as flow in a pipe. Internal flow dealing with cooling or heating is usually treated using convection correlations [12].

Many empirical correlations for calculating the heat transfer coefficient for fully developed internal flow can be found in the literature. The recent and more accurate correlation recommended by the Handbook of Heat Transfer is the Gnielinski correlation which is accurate within $\pm 10 \%$ in the range of $0.5 \leq \operatorname{Pr} \leq 106$ and $2300 \leq \operatorname{Re}_{D} \leq 5 \times 10^{6}$ [15].

$\bar{N} u_{D}=0.0214\left(\operatorname{Re}_{D}^{0.8}-100\right) \operatorname{Pr}^{0.4}$

Valid in the range $\quad 0.5 \leq \operatorname{Pr} \leq 1.5, \quad 10^{4} \leq \operatorname{Re}_{D} \leq 10^{6}$

$\bar{N} u_{D}=0.021\left(\operatorname{Re}_{D}^{0.87}-280\right) \operatorname{Pr}^{0.4}$

Valid in the range $\quad 1.5 \leq \operatorname{Pr} \leq 500, \quad 3 \times 10^{3} \leq \operatorname{Re}_{D} \leq 10^{6}$

For internal flows, the mean bulk temperature is a convenient reference temperature and the properties of water inside the pipe are determined at the mean bulk temperature. For the first iteration, the properties are evaluated at the water inlet 
temperature, $T_{w i}$. As the iteration process proceeds, this temperature is corrected to the bulk temperature, which is $\left(T_{w o}-T_{w i}\right) / 2$.

For the internal flow, Reynolds number is given by:

$$
\operatorname{Re}_{D}=\frac{\rho_{w} \bar{V} D}{\mu_{w}}=\frac{4 \dot{m}_{w}}{\pi D \mu_{w}}
$$

The average heat transfer coefficient can be obtained as:

$$
\bar{h}_{i}=\frac{\bar{N} u_{i} K_{w}}{D}
$$




\subsection{Overall heat-transfer Coefficient}

After obtaining all the heat transfer coefficients, the following equation can be used for calculating the overall heat transfer coefficient [11].

$U=\left(\left(A R_{o t}\right)+\frac{1}{\bar{h}_{\text {cond }}}+\frac{1}{\bar{h}_{i}}\right)$

The LMTD method is used to calculate the overall heat transfer rate, $q$ :

$q=F U A \Delta T_{l m}$

Where the log mean temperature difference is given by:

$$
\begin{aligned}
& \Delta T_{l m}=\left(\frac{\left(T_{1}-T_{w i}\right)-\left(T_{1}-T_{w o}\right)}{\ln \frac{\left(T_{1}-T_{w i}\right)}{\left(T_{1}-T_{w o}\right)}}\right) \\
& q=F U A\left(\frac{\left(T_{1}-T_{w i}\right)-\left(T_{1}-T_{w o}\right)}{\ln \frac{\left(T_{1}-T_{w i}\right)}{\left(T_{1}-T_{w o}\right)}}\right)
\end{aligned}
$$

Where $T_{w i}$ and $T_{w o}$ are the domestic water inlet and outlet temperatures respectively.

Note that this situation can be treated as a pure counter flow, since the temperature on the outside of the condenser film is essentially constant. Therefore, the correction factor is 
unity $(F \approx 1)[11]$. Solving the above equations for the domestic water outlet temperature $T_{w o}$ yields:

$$
\begin{aligned}
& \dot{m}_{w} C p_{w}\left(T_{w o}-T_{w i}\right)=F U A\left(\frac{\left(T_{1}-T_{w i}\right)-\left(T_{1}-T_{w o}\right)}{\ln \frac{\left(T_{1}-T_{w i}\right)}{\left(T_{1}-T_{w o}\right)}}\right) \\
& T_{w o}=T_{1}-\left(T_{1}-T_{w i}\right) \exp \left(-\frac{U A}{\dot{m}_{w} C p_{w}}\right)
\end{aligned}
$$

Using the value of $T_{w o}$, an improved estimate of the total heat transfer rate to the condenser coils can be obtained:

$$
q=\dot{m}_{w} C p_{w}\left(T_{w o}-T_{w i}\right)
$$

After calculating the total heat transfer rate for the heat exchanger, a better estimate of the interface temperature $\bar{T}_{i}$ can be made. Referring to the thermal resistance diagram in Figure 3, the improved interface temperature is

$$
\bar{T}_{i}=T_{1}-q R_{o t}
$$

To proceed with the next iteration, an improved estimate of the temperature drop across the condensate film $\bar{T}_{i}-\bar{T}_{s}$ is needed. This quantity can be obtained using the 
improved heat-transfer rate and the condensation heat-transfer coefficient $\bar{h}_{\text {cond }}$ as follows:

$$
\bar{T}_{i}-\bar{T}_{s}=\frac{q}{\bar{h}_{\text {cond }} A}
$$

Improved values have now been calculated for all the parameters that were guessed in the first iteration. For the iteration procedure, the commercially available heat transfer software EES [2] has been used (for EES sample calculations, see Appendix B). The procedure described above can be repeated until convergence is achieved. 


\subsection{Condition after the Coil}

The heat exchanger in this heat recovery dryer has four banks of vertically arranged horizontal tubes and it is required to calculate the heat transfer rate for each tube bank. The analysis in this case proceeds along the same lines with the outlet conditions of the first bank becoming the inlet conditions for the second bank, and so on.

The composition of a given moist air can be described by means of the humidity ratio $w$, defined as the ratio of the mass of the water vapour to the mass of the dry air.

$$
w=\frac{\dot{m}_{v}}{\dot{m}_{a}}
$$

If the heat exchanger is treated as a control volume, then, at steady state, the amount of dry air and water vapour contained in a control volume can not vary. Thus, for each component, the incoming and outgoing mass flow rates must be equal.

$$
\begin{aligned}
& \dot{m}_{a 1}=\dot{m}_{a 2} \text { (Dry air) } \\
& \dot{m}_{v 2}+\dot{m}_{w 1}=\dot{m}_{v 1} \text { (Water) }
\end{aligned}
$$

The mass flow rates of water vapour can be expressed in terms of humidity ratios as $\dot{m}_{v 1}=w_{1} \dot{m}_{a}$ and $\dot{m}_{v 2}=w_{2} \dot{m}_{a}$, and the mass balance for water vapour can be expressed as $\dot{m}_{w}=\dot{m}_{a}\left(w_{1}-w_{2}\right)$, where $w_{1}$ and $w_{2}$ are the values of specific humidity before and after the coil, respectively, and the humidity ratio for the state 2 can be expressed as 


$$
w_{2}=w_{1}-\frac{\dot{m}_{v}}{\dot{m}_{a}}
$$

Similarly, for this problem, the conditions at state 2 (after the first bank) can be calculated using the condensation rate $\dot{m}_{v}$ and the mass flow rate of dry air $\dot{m}_{a}$ on the first coil. The specific humidity before the coil, $w_{1}$, can be determined by assuming ideal gas behaviour as:

$$
w_{1}=\frac{P_{v 1} V M_{v} / R T_{1}}{P_{a 1} V M_{a} / R T_{1}}
$$

$$
w_{1}=\frac{M_{v} P_{v 1}}{M_{a} P_{a 1}}
$$

In the moist air condition, the ratio of molecular weight of water vapour to that of dry air is approximately 0.622 and the above equation can be written as:

$$
w_{1}=0.622 \frac{P_{v 1}}{P_{a 1}}
$$

The mass flow rate of the dry air can be determined by ideal gas law as:

$$
\dot{m}_{a}=\rho_{a} Q=\frac{P_{a} M_{a}}{R T_{1}} Q
$$

Evaluating Equation 3.52 and using the mass flow rate of dry air and the condensation rate from converged solution, the humidity ratio after the first tube bank can be calculated. 
The moist air outlet temperature of the coil is unknown. An energy balance or the first law analysis can be used to determine the outlet temperature that will be the free stream temperature of the second tube bank. The energy rate balance reduces at the steady state to:

$q=\dot{m}_{a}\left[\left(h_{a 2}-h_{a 1}\right)-w_{1} h_{v l}+w_{2} h_{v 2}+\left(w_{1}-w_{2}\right) h_{l}\right]$

where $h_{a 1}$ and $h_{a 2}$ are the enthalpies of the dry air, $h_{\nu 1}$ and $h_{\nu 2}$ are the enthalpies of the water vapour at the tube bank inlet and outlet temperature respectively, and $h_{l}$ is the enthalpy of liquid water at inlet temperature.

An iterative solution procedure is used to calculate the outlet temperature of the first tube bank or the inlet temperature of the second tube bank. For the iteration procedure, the commercially available EES software [2] has been used. To initiate the iteration process, a "guess" value for this temperature is assumed to get the enthalpy values until the above equation converges. The temperature at which the convergence is achieved will be the free stream temperature for the second tube bank. Using this free stream temperature $T_{2}$ and the specific humidity ratio $w_{2}$, the conditions for state 2 can be determined completely.

After determining the condition for state 2 , the analysis proceeds along the same lines as the first tube bank. The heat transfer rate for all four tube banks can be calculated with the outlet conditions of the first bank becoming the inlet conditions for the second bank, and so on. 


\subsection{Coils Pressure Drop Calculation}

When fluid is passed across a tube bank, a pressure drop develops across the bank from the inlet to the outlet. This pressure drop must be known if the pumping power required by a fan to move the fluid through the bank is to be ascertained. To calculate the pressure drop, Hegan proposed the following relation [16]:

$$
\Delta P=N_{L} \Phi \frac{\rho_{m} U_{\max }^{2}}{2} f
$$

Where the friction factor $f$ and the correction factor $\Phi$, for staggered tube, are determined using Figure 4, and $N_{L}$ is the number of rows in the tube bank. The value $\rho_{m}$ is the mean inlet density of the fluid and $U_{\max }$ is the maximum velocity of the fluid.

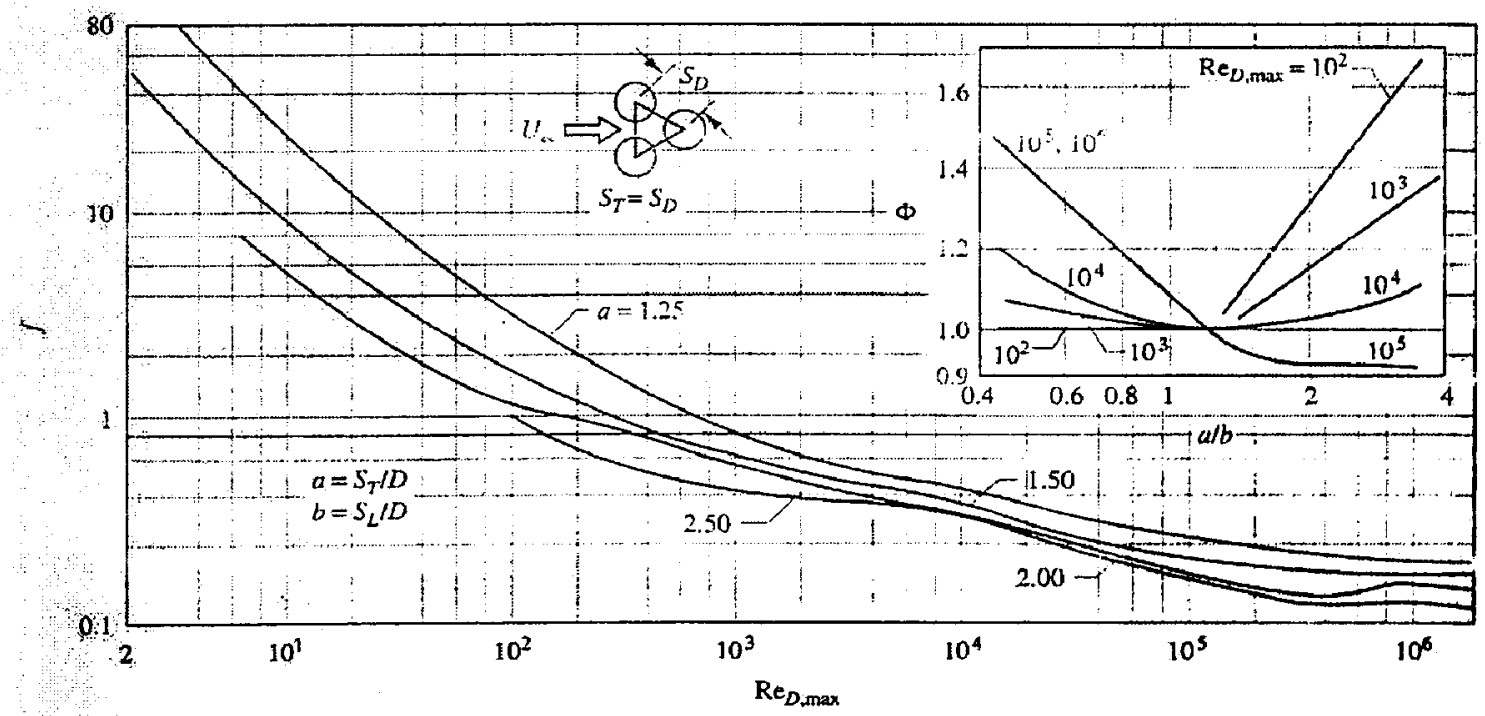

Figure 4. Friction factor for a staggered tube bank as a function of the Reynolds number [16] 
In a staggered tube bank, altering rows are offset by one half of the tube spacing. The spacing that is parallel and perpendicular to the flow direction is defined as the longitudinal pitch, $S_{L}$, and transverse pitch, $S_{T}$, respectively. The Reynolds number, $R e_{D \max }$ is based on the maximum velocity $U_{\max }$ that occurs in the tube bank. For staggered tube banks, the maximum velocity occurs at either the transverse plane $P_{1}$ or $P_{2}$ as shown in Figure 5, depending on the spacing of tubes in the bank. The maximum velocity $U_{\max }$, occurs at the transverse plane, $P_{1}$. From the conservation of mass principle, the maximum velocity is [16]:

$U_{\max }=\frac{S_{T}}{S_{T}-D} \bar{V}$

If the tubes are spaced such that,

$S_{D}<\frac{S_{T}+D}{2}$

The maximum velocity, $U_{\max }$, occurs at $P_{2}$ and the maximum velocity $U_{\max }$ is:

$U_{\max }=\frac{S_{T}}{2\left(S_{D}-D\right)} \bar{V}$

Where, by the Pythagorean theorem, $S_{D}$ is

$S_{D}=\sqrt{S_{L}^{2}+\left(\frac{S_{T}}{2}\right)^{2}}$

In Figure 4, $a=\frac{S_{T}}{D}, b=\frac{S_{L}}{D}$ 


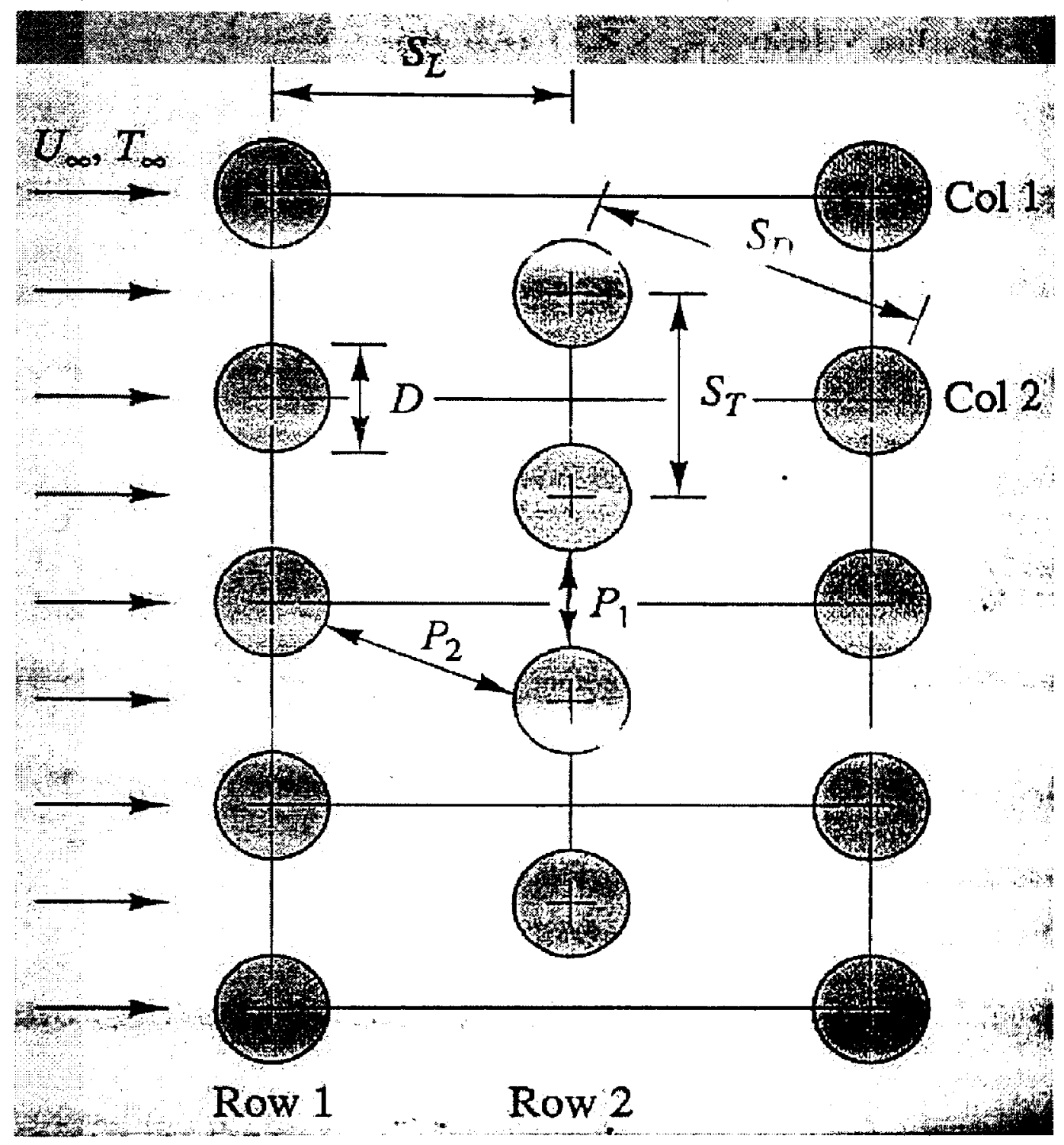

Figure 5. Tube arrangement in a staggered tube bank [16] 


\subsection{Suction Velocity}

In a steady state condition, condensation occurs at the liquid film interface on the wall. As a result of the condensation process at the interface, there is a bulk velocity of the air towards the wall, as if there is suction at the interface. Only the water vapour condenses; therefore, the water concentration is reduced and suction is induced at the interface [17].

At a steady state condition, the condensation rate can be defined as:

$$
\dot{m}_{v}=\rho_{m} A V_{i} m_{v i}
$$

or

$$
V_{i}=\frac{\dot{m}_{v}}{\rho_{m} A m_{v i}}
$$

Where $v_{i}$ is the interface suction velocity and $m_{i}$ is the mass fraction of vapour at interface 


\section{CHAPTER 4 \\ Results and Discussion}

Using the solution procedure described in Chapter 3, the converged results for all four coils are tabulated in Table 1.

Table 1. Tabulated results

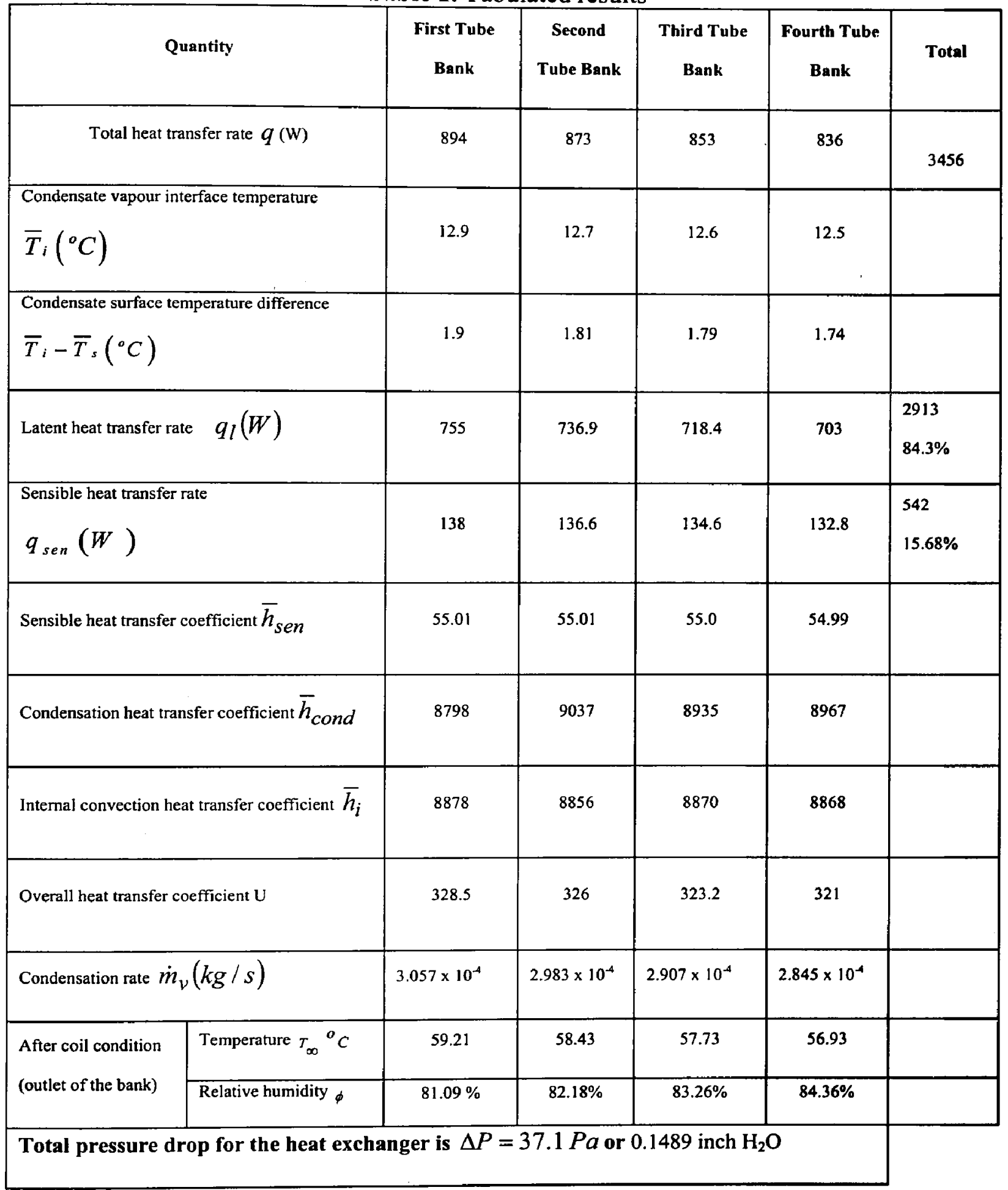


The basis of this heat and mass transfer problem was the energy balance at the interface, and the heat transfer from the gas phase was viewed as made up of sensible cooling of non-condensable gas and the contribution due to mass transfer, that is, the latent heat due to condensation of the diffused vapour at the interface. Separate models for the calculation of latent and sensible heat transfer were used. The mass transfer coefficients were obtained from an analogy with heat transfer, and the unknown interface temperature was solved for iteratively.

The tabulated results show that the condensation of vapour contributed more to the heat transfer than the sensible heat component. The latent heat transfer is $84.3 \%$ of the total heat transfer, whereas the sensible heat transfer is $15.68 \%$ of the total heat transfer. Thus, the latent heat component is 5 times higher than the sensible heat component.

Heat transfer by radiation was not taken into account and the effects of interfacial shear stress were neglected. It can be seen in the appendix that the suction effect for this problem was found to be $17 \%$ of the free stream velocity, and therefore it was ignored. The mass transfer effects were the main resistance to the condensation heat transfer. Hence, it is not expected that the improvement of the condensation model would improve the heat transfer rate.

From the results, it can also be observed that after the first coil, the free stream temperature reduced by $0.8^{\circ} \mathrm{C}$ and the relative humidity increased by $1.1 \%$; hence, the heat transfer rate in the second coil was reduced by $21 \mathrm{~W}$. Similarly, a reduction in 
temperature can be observed in the third coil, but the heat transfer rate was reduced by only $20 \mathrm{~W}$. It is evident that the heat transfer rate decreased by $17 \mathrm{~W}$ in the fourth coil, and the reason for this could be the $4 \%$ increase in the relative humidity while the dry bulb temperature decreased.

The main purpose of this project was to determine the amount of heat available to be recovered from an industrial cloth dryer. The data for this design was collected from a $20 \mathrm{~kW}$ dryer, and the heat recovery from that dryer was observed to be about $17.3 \%$.

A similar model was studied for a single coil by Naylor and Oosthuizen [11] in which heat transfer only by the diffusion of vapour was considered. Furthermore, the free stream temperature and relative humidity were considered as $45^{\circ} \mathrm{C}$ and $90 \%$, respectively. The heat transfer rate calculated for the single coil was $375 \mathrm{~W}$. A significant improvement can be observed in the present model where both the latent heat transfer and the sensible heat transfer were considered, and the free stream temperature was taken as $60^{\circ} \mathrm{C}$ with $80 \%$ relative humidity. The average overall heat transfer rate was 2.3 times higher than that in the previous study done by [11]. The average latent heat transfer rate was 1.9 times higher than that in the previous study. The reason for the improvement in latent heat transfer was that the warm air $\left(60^{\circ} \mathrm{C}\right)$ carried more moisture than the cold air $\left(45^{\circ} \mathrm{C}\right)$. The improvement in the overall heat transfer rate due to the sensible heat was only $16 \%$ on average. This condensing heat exchanger efficiency can be improved by adding more coils to the heat exchanger, provided that the pressure drop in the heat exchanger is kept to a permissible value. 
The derivation of the present model was based on the empirical correlations in terms of dimensionless thermal parameters and experimentally measured constants; hence, these correlations can be expected to yield only estimates. These correlations do not account for the free stream turbulence in the second coil that can contribute to an increase in the heat transfer rate for the second coil and the coils after it. An improvement can be expected if a practical study is done on the condensation heat exchanger for an industrial electric clothes dryer. 


\section{Appendix A - Sample Mathematical Calculations}

Dry air temperature at free stream is $T_{1}=60^{\circ} \mathrm{C}$ and relative humidity $R H=80 \%$,

For the first iteration, a good guess for the interfacial temperature is to take twice the value of the water inlet temperature $\left(8^{\circ} \mathrm{C}\right)$. Then, the interfacial guess temperature is $\bar{T}_{i}=16^{\circ} \mathrm{C}$

Film temperature of the dry exhaust air can be calculated as:

$$
\bar{T}_{f}=\frac{60+16}{2}=38^{\circ} \mathrm{C}
$$

The saturated vapour pressure at the interface temperature $\bar{T}_{i}=16^{\circ} \mathrm{C}$ is $P_{v i}=2339 \mathrm{~Pa}$

The vapour density at the interface condition can be calculated by using the ideal gas law:

$$
\rho_{v i}=\frac{P_{v i} M_{v}}{R \bar{T}_{i}}=\frac{(1819)(18)}{(8314)(289)}=0.0136 \mathrm{~kg} / \mathrm{m}^{3}
$$

To calculate the air density at the interface, a similar procedure can be used.

$$
\rho_{a i}=\frac{P_{a i} M_{a}}{R \bar{T}_{i}}=\frac{(100000-1819)(29)}{(8314)(289)}=1.184 \mathrm{~kg} / \mathrm{m}^{3}
$$

The relative humidity at the free stream condition is $\phi_{1}=80 \%$, the temperature is $60^{\circ} \mathrm{C}$, and the vapour saturation pressure at this temperature is $P_{\text {sat }}=19932 \mathrm{~Pa}$. At free stream condition, the partial pressure of water vapour is

$$
P_{v 1}=\phi P_{\text {sat } 1}=15946 \mathrm{~Pa}
$$


The free stream water vapour density can be calculated by using the ideal gas law as:

$$
\rho_{v 1}=\frac{P_{v 1} M_{v}}{R T_{1}}=\frac{(15946)(18)}{(8314)(333)}=0.1038 \mathrm{~kg} / \mathrm{m}^{3}
$$

Similarly, the ideal gas law can be used to calculate the free stream air density:

$$
\rho_{a 1}=\frac{P_{a 1} M_{a}}{R T_{1}}=\frac{(84054)(29)}{(8314)(333)}=0.8794 \mathrm{~kg} / \mathrm{m}^{3}
$$

From the above density values, the interface mass fraction of water vapour can be calculated as follows:

$$
m_{i}=\frac{\rho_{v i}}{\rho_{v i}+\rho_{a i}}=\frac{0.0136}{0.0136+1.184}=0.0114
$$

Similarly, the mass fraction of vapour at the free stream is:

$$
m_{1}=\frac{\rho_{v 1}}{\rho_{v 1}+\rho_{a 1}}=\frac{0.1038}{0.1038+0.8794}=0.1055
$$

Mean density of the dry air-vapour mixture can be calculated as:

$$
\begin{gathered}
\rho_{m}=\frac{\left(\rho_{v i}+\rho_{a i}\right)+\left(\rho_{v 1}+\rho_{a 1}\right)}{2} \\
\rho_{m}=\frac{(0.0173+1.161)(0.1038+0.8794)}{2}=1.081 \mathrm{~kg} / \mathrm{m}^{3}
\end{gathered}
$$


The approximate film temperature is $\bar{T}_{f}=\frac{T_{1}+\bar{T}_{i}}{2}=\frac{60+16}{2}=38^{\circ} \mathrm{C}$. The air and mass transfer properties are calculated at the film temperature

$$
\delta=0.26 \times 10^{-6}\left(\frac{311}{298}\right)^{3 / 2}=2.772 \times 10^{-5} \mathrm{~m}^{2} / \mathrm{s}
$$

Mixture viscosity is calculated by Wilke [13] method.

\section{Calculation for Mixture Viscosity Using Wilke Method}

The free stream total pressure $P=100 \mathrm{kPa}$, the free stream humidity $\phi=80 \%$ and all the properties are calculated at film temperature: $\bar{T}_{f}=38^{\circ} \mathrm{C}$

Water vapour viscosity at $\bar{T}_{f}=38^{\circ} \mathrm{C}$ is $\mu_{v}=10.25 \times 10^{-6} \frac{\mathrm{Ns}}{\mathrm{m}^{2}}$

Air viscosity at $\bar{T}_{f}=38^{\circ} \mathrm{C}$ is $\mu_{a}=190.9 \times 10^{-7} \frac{\mathrm{Ns}}{\mathrm{m}^{2}}$

Molecular weight for water $=18.015$

Molecular weight for air $=28.97$

Introducing the above values in the relationship given by Wilke:

$$
\begin{gathered}
\varphi_{a v}=\frac{\left[1+\left(\mu_{a} / \mu_{v}\right)^{1 / 2}\left(M_{v} / M_{a}\right)^{1 / 4}\right]^{2}}{(4 / \sqrt{2})\left[1+\left(M_{a} / M_{v}\right)\right]^{1 / 2}} \\
\varphi_{a v}=\frac{\left[1+(19.09 / 10.25)^{1 / 2}(18.015 / 28.97)^{1 / 4}\right]^{2}}{(4 / \sqrt{2})[1+(28.97 / 18.015)]^{1 / 2}} \\
\varphi_{a v}=1.071
\end{gathered}
$$




$$
\begin{gathered}
\varphi_{v a}=\frac{\left[1+\left(\mu_{v} / \mu_{a}\right)^{1 / 2}\left(M_{a} / M_{v}\right)^{1 / 4}\right]^{2}}{(4 / \sqrt{2})\left[1+\left(M_{v} / M_{a}\right)\right]^{1 / 2}} \\
\varphi_{v a}=\frac{\left[1+(10.25 / 19.09)^{1 / 2}(28.97 / 18.015)^{1 / 4}\right]^{2}}{(4 / \sqrt{2})[1+(18.015 / 28.97)]^{1 / 2}} \\
\varphi_{v a}=0.9246
\end{gathered}
$$

At film temperature, the vapour pressure is $P_{v s a t}=0.0663 \mathrm{bar}$ and the partial pressure of the vapour is:

$$
P_{v}=\phi P_{v s a t}=0.8(0.0663)=0.0530 \mathrm{bar}
$$

Mole fraction will be the partial pressure of each component.

$$
\begin{gathered}
x_{v}=0.0530 \\
x_{a}=1-0.0530=0.9469 \\
\mu_{m}=\frac{\mu_{v}}{1+\frac{x_{a}}{x_{v}} \varphi_{v a}}+\frac{\mu_{a}}{1+\frac{x_{v}}{x_{a}} \varphi_{a v}} \\
\mu_{m}=\frac{10.25}{1+\frac{0.9469}{0.0530}(0.9246)}+\frac{19.09}{1+\frac{0.0530}{0.9469}(1.071)}
\end{gathered}
$$


The mixture viscosity is

$$
\mu_{m}=18.47 \times 10^{-6} \frac{N s}{m^{2}}
$$

Mixture kinematic viscosity is:

$$
\begin{gathered}
v=\frac{\mu_{m}}{\rho_{m}}=\frac{18.47 \times 10^{-6}}{1.09}=16.94 \times 10^{-6} \mathrm{~m}^{2} / \mathrm{s} \\
S c=\frac{v}{\delta}=\frac{16.94 \times 10^{-6}}{2.772 \times 10^{-5}}=0.6112
\end{gathered}
$$

The exhaust gas volume flow rate is $Q=0.13 \mathrm{~m}^{3} / \mathrm{Sec}$, and the cross sectional area of the exhaust is $A_{c}=0.04 \mathrm{~m}^{2}$. The velocity of the exhaust gas will be $\bar{V}=\frac{0.13}{0.04}=3.25 \mathrm{~m} / \mathrm{s}$. The Reynolds number for the exhaust gas can be calculated as follows:

$$
\operatorname{Re}_{D}=\frac{\rho_{m} \bar{V} D}{\mu_{m}}=\frac{(1.09)(3.25)(0.01)}{1.847 \times 10^{-5}}=1918
$$

For $\operatorname{Re}_{D}=1918$, the values of Hilpert's [12] correlation constants are $C=0.683$ and $m=0.466$ (see Appendix C)

$$
\begin{gathered}
\overline{S h}=C \operatorname{Re}_{D}^{m} S c^{1 / 3} \\
\overline{S h}=0.683(1918)^{0.466}(0.6112)^{1 / 3}=19.63
\end{gathered}
$$


Hence, the convective mass transfer conductance $g_{m}$ is

$$
\begin{gathered}
g_{m}=\frac{\rho_{m} \overline{S h} \delta}{D} \\
g_{m}=\frac{(1.09)(19.63)\left(2.772 \times 10^{-s}\right)}{0.01}=0.0593 \mathrm{~kg} / \mathrm{m}^{2} \mathrm{~s}
\end{gathered}
$$

The mass transfer rate which is equal to the condensation rate is given by

$$
\dot{m}_{v}=g_{m} A\left(m_{v 1}-m_{v i}\right)
$$

The total surface pipe surface area $A=\pi D L=\pi(0.01)(1.7)=0.0534 \mathrm{~m}^{2}$

Introducing the above calculated values in the condensation rate equation, the condensation rate is:

$$
\dot{m}_{v}=(0.0593)(0.0534)(0.1055-0.01139)=2.983 \times 10^{-4} \mathrm{~kg} / \mathrm{s}
$$

The latent heat transfer rate required to condense vapour at this rate is:

$$
q_{l}=\dot{m}_{v} h_{f g}=\left(2.983 \times 10^{-4}\right)(2463000)=734.7 \mathrm{~W}
$$

The effective thermal resistance due to mass transfer can be calculated as:

$$
R_{\text {mass }}=\frac{\left(T_{1}-\bar{T}_{i}\right)}{q_{l}}=\frac{(60-16)}{734.7}=0.0599^{\circ} \mathrm{C} / \mathrm{W}
$$


Sensible Heat Transfer

The film temperature is $\bar{T}_{f}=38^{\circ} \mathrm{C}$

The viscosity of dry exhaust mixture is $\mu_{m}=18.47 \times 10^{-6} \mathrm{~N} \mathrm{~s} / \mathrm{m}^{2}$

$\operatorname{Pr}=0.726$

$K_{\text {air }}=26.47 \times 10^{-3} \mathrm{~W} / \mathrm{mK}$

The Reynolds number as calculated above is $\mathrm{Re}_{D}=1918$

To calculate the sensible heat transfer coefficient, the Hilpert correlation is used and for $\operatorname{Re}_{D}=1918$, the Hilpert constants are $C=0.683$ and $m=0.466$

$$
\begin{gathered}
\bar{N} u=C \operatorname{Re}_{D}^{m} P r^{1 / 3} \\
\bar{N} u=0.683(1918)^{0.466}(0.726)^{1 / 3}=20.79
\end{gathered}
$$

The sensible heat transfer coefficient is:

$$
\bar{h}_{\text {sen }}=\bar{N} u \frac{K_{a i r}}{D}=(20.79) \frac{26.47 \times 10^{-3}}{0.01}=55.04 \mathrm{~W} / \mathrm{m}^{2} \mathrm{~K}
$$

The effective thermal resistance for sensible heat transfer is:

$$
R_{\text {sen }}=\frac{1}{\bar{h}_{\text {sen }} A}=\frac{1}{(55.04)(0.0534)}=0.3402^{\circ} \mathrm{C} / \mathrm{W}
$$

The total free stream mass and sensible transfer resistance is:

$$
R_{o t}=\left(\frac{1}{R_{\text {mass }}}+\frac{1}{R_{\text {sen }}}\right)^{-1}=\left(\frac{1}{0.0599}+\frac{1}{0.3402}\right)^{-1}=0.051^{\circ} \mathrm{C} / \mathrm{W}
$$




\section{Condensation Heat Transfer}

The correlation to calculate the condensation heat transfer over the tube bank is as follows [4]:

$$
\bar{N} u_{\text {cond }}=\frac{\bar{h}_{\text {cond }}(n D)}{K_{l}}=0.729\left[\frac{g h_{f g} \rho_{l}\left(\rho_{l}-\rho_{\nu}\right)(n D)^{3}}{\mu_{l} k_{l}\left(\overline{T_{i}}-\overline{T_{s}}\right)}\right]^{1 / 4}
$$

All the liquid water properties are evaluated at $\left(\bar{T}_{s}+\bar{T}_{i}\right) / 2=12^{\circ} \mathrm{C}$ for the first iteration as follows:

Condensate thermal conductivity $K_{l}=0.5674 \mathrm{~W} / \mathrm{mK}$

Condensate density $\rho_{l}=1000 \mathrm{~kg} / \mathrm{m}^{3}$

Condensate viscosity $\mu_{i}=1.037 \times 10^{-3} \mathrm{Ns} / \mathrm{m}^{2}$

The latent heat of vaporization is calculated at the interface temperature $\bar{T}_{i}=16^{\circ} \mathrm{C}$, that is $h_{f g}=2453 \mathrm{~kJ} / \mathrm{kgK}$

The density of vapour in this problem is very small; therefore, it is assumed that the term $\rho_{l}\left(\rho_{l}-\rho_{v}\right)$ is approximately equal to $\rho_{l}^{2}$. There are nine staked pipes $(n=9)$ in this heat exchanger. Introducing all the above values in the above correlation,

$$
\bar{N} u_{c o n d}=0.729\left[\frac{(9.81)\left(2463 \times 10^{3}\right)(1000)^{2}(9 \times 0.01)^{3}}{\left(1.037 \times 10^{-3}\right)(0.5674)(12)}\right]^{1 / 4}=864.6
$$


The average condensation heat transfer coefficient $\bar{h}_{\text {cond }}$ can be calculated as:

$$
\begin{gathered}
\bar{h}_{c o n d}=\frac{\bar{N} u_{c o n d} K_{l}}{n D}=\frac{(864.6)(0.5674)}{9(0.01)}=5451 \mathrm{~W} / \mathrm{m}^{2} K \\
\bar{h}_{\text {cond }}=5451 \mathrm{~W} / \mathrm{m}^{2} \mathrm{~K}
\end{gathered}
$$

\section{Internal Forced Convection}

The most recent correlation for the internal flow inside a pipe by Gnielinski is as follows [4]:

$$
\bar{N} u_{i}=0.012\left(\operatorname{Re}_{D}^{0.87}-280\right) \operatorname{Pr}^{0.4}
$$

Where $1.5 \leq \operatorname{Pr} \leq 500$ and $3 \times 10^{3} \leq \operatorname{Re}_{D} \leq 10^{6}$

All the properties are calculated at water bulk temperature which is $\left(T_{w o}+T_{w 1}\right) / 2$. For the first iteration, the properties are determined at water inlet temperature $T_{w i}=8^{\circ} \mathrm{C}$ as follows:

Water conductivity $K_{w}=0.564 \mathrm{~W} / \mathrm{mK}$

The specific heat of water $C p_{w}=4192 \mathrm{~J} / \mathrm{kgK}$

The density of water $\rho_{w}=1000 \mathrm{~kg} / \mathrm{m}^{3}$

The viscosity of water $\mu_{w}=1.386 \times 10^{-3} \mathrm{Ns} / \mathrm{m}^{2}$

Prandtl number $\operatorname{Pr}_{w}=10.31$ 
The volume flow rate of water inside the pipe is $6 \mathrm{~L} / \mathrm{min}$ and the mass flow rate of the water inside the pipe is $\dot{m}_{w}=0.1 \mathrm{~kg} / \mathrm{s}$

For the internal flow, Reynolds number can be calculated as:

$$
\operatorname{Re}_{D}=\frac{\rho_{w} \bar{V} D}{\mu_{w}}=\frac{4 \dot{m}_{w}}{\pi D \mu_{w}}=\frac{4(0.1)}{\pi(0.01)\left(1.386 \times 10^{-3}\right)}=13128
$$

The $\operatorname{Re}_{D}=13128$ is turbulent, and introducing the Reynolds number and Prandtl number in the above internal flow correlation,

$$
\bar{N} u_{i}=0.012\left((13128)^{0.85}-280\right)(10.31)^{0.4}=108.2
$$

The average heat transfer coefficient can be obtained as

$$
\begin{gathered}
\bar{h}_{i}=\frac{\bar{N} u_{i} K_{w}}{D}=\frac{108.2(0.5635)}{0.01}=8711 \mathrm{~W} / \mathrm{m}^{2} \mathrm{~K} \\
\bar{h}_{i}=8711 \mathrm{~W} / \mathrm{m}^{2} \mathrm{~K}
\end{gathered}
$$


The overall heat transfer coefficient is calculated as follows:

$$
\begin{gathered}
U=\left(\left(A R_{o t}\right)+\frac{1}{\bar{h}_{c o n d}}+\frac{1}{\bar{h}_{i}}\right) \\
U=\left((0.0534)(0.051)+\frac{1}{5451}+\frac{1}{8711}\right)^{-1} \\
U=331.4 \mathrm{~W} / \mathrm{m}^{2} K
\end{gathered}
$$

The LMTD method is used to calculate the overall heat transfer rate $q$

$$
\begin{gathered}
q=F U A \Delta T_{l m}=F U A\left[\frac{\left(T_{1}-T_{w i}\right)-\left(T_{1}-T_{w o}\right)}{\ln \frac{\left(T_{1}-T_{w i}\right)}{\left(T_{1}-T_{w o}\right)}}\right] \\
q=\dot{m} c_{p w}\left(T_{w o}-T_{w i}\right) \\
\dot{m} c_{p w}\left(T_{w o}-T_{w i}\right)=F U A\left[\frac{\left(T_{1}-T_{w i}\right)-\left(T_{1}-T_{w o}\right)}{\ln \frac{\left(T_{1}-T_{w i}\right)}{\left(T_{1}-T_{w o}\right)}}\right]
\end{gathered}
$$


Solving the above equations for the domestic water outlet temperature $\bar{T}_{w o}$,

$$
\begin{gathered}
T_{w o}=\exp \left(\frac{-U A}{\dot{m}_{w} c_{p w}}\right)\left(T_{w i}-T_{1}\right)+T_{1} \\
T_{w o}=\exp \left(-\frac{331.4(0.0534)}{0.1(4192)}\right)(8-60)+60=10.15^{\circ} \mathrm{C}
\end{gathered}
$$

Using this result, an improved estimate of the total heat-transfer rate to the condenser coils can be obtained:

$$
q=\dot{m}_{w} C p_{w}\left(T_{w o}-T_{w i}\right)=0.1(4192)(10.15-8)=901 W
$$

\section{Condition after the Coil}

To estimate the after-coil condition, an energy balance or first law analysis for the heat exchanger is given as follows:

$$
-q=\dot{m}_{a}\left[\left(h_{a 2}-h_{a 1}\right)-w_{1} h_{v 1}+w_{2} h_{v 2}+\left(w_{1}-w_{2}\right) h_{l}\right]
$$

Where $h_{a 1}$ and $h_{a 2}$ are the enthalpies of the dry air and $h_{v 1}$ and $h_{v 2}$ are the enthalpies of water vapour at the tube bank inlet and outlet temperature respectively, and $h_{l}$ is the enthalpy of water, at water inlet temperature. 
The specific humidity at the inlet is calculated as:

$$
w_{1}=0.622 \frac{P_{v 1}}{P_{a 1}}
$$

Where, $P_{v 1}$ and $P_{a 1}$ are the free stream vapour pressure and air pressure respectively, calculated at free stream temperature $T_{1}=60^{\circ} \mathrm{C}$

$$
w_{1}=0.622 \frac{(15946)}{(100000-15946)}=0.1180 \frac{\mathrm{kg} \text { of } \mathrm{H}_{2} \mathrm{O}}{\mathrm{kg} \text { of dry air }}
$$

The mass flow rate of dry air is

$$
\begin{gathered}
\dot{m}_{a}=\rho_{a} Q \\
\dot{m}_{a}=\rho_{a} Q=\frac{P_{a 1} M_{a}}{R \bar{T}_{1}} Q \\
\dot{m}_{a}=\frac{(100000-15946) 28.9}{(8.314)(333)}(0.13)=0.114 \mathrm{~kg} / \mathrm{s}
\end{gathered}
$$

Using the condensation rate for the converged solution, air mass flow rate and the specific humidity $w_{1}$, the specific humidity at the outlet of the first coil $w_{2}$ can be calculated as follows:

$$
w_{2}=w_{1}-\frac{\dot{m}_{v}}{\dot{m}_{a}}=0.1180-\frac{1.53 \times 10^{-4}}{0.114}=0.1153
$$


To initiate the iterative solution to calculate the moist air outlet temperature of the first tube bank, a value of $T_{2}=59^{\circ} \mathrm{C}$ is assumed (note that for the first iteration a good guess for the coil outlet temperature is to take $1^{\circ} \mathrm{C}$ less than the free stream inlet temperature). At this temperature, the enthalpy of the air and water vapour are determined from the tabulated data as follows:

$$
\begin{gathered}
h_{a 1}=333808, \quad h_{a 2}=332801, \\
h_{v 1}=2.609 \times 10^{6}, \quad h_{v 2}=2.607 \times 10^{6} \\
h_{l}=42532
\end{gathered}
$$

From the converged solution for coil 1(See Appendix B) the total heat transfer rate $q$ was calculated as $894 \mathrm{~W}$ and the equation below should converged to $q=894 \mathrm{~W}$

$$
\begin{gathered}
-q=0.114\left[(332801-333808)-0.1180\left(2.609 \times 10^{6}\right)+0.1153\left(2.607 \times 10^{6}\right)+(0.1180-0.115\right. \\
-q[-894] \neq-923 W
\end{gathered}
$$

From the above calculation, it can be noticed that convergence to the heat transfer rate has not been achieved at the guess temperature $T_{2}=59^{\circ} \mathrm{C}$. A new temperature value is guessed each time until the convergence is achieved. The complete converged solution has been achieved using EES, and the EES solution is attached in the Appendix. 


\section{Coils Pressure Drop Calculation}

For this heat exchanger design, the values of $S_{T}$ and $S_{L}$ can be determine from Figure 1 .

Where,

$$
\begin{aligned}
& S_{L}=0.02 \mathrm{~m} \\
& S_{T}=0.02 \mathrm{~m}
\end{aligned}
$$

Tube diameter, $D=0.01 \mathrm{~m}$

Then

$$
S_{D}=\sqrt{S_{L}^{2}+\left(\frac{S_{T}}{2}\right)^{2}}=\sqrt{0.02^{2}+\left(\frac{0.02}{2}\right)^{2}}=0.02236 \mathrm{~m}
$$

Applying the test,

$$
S_{D}<\frac{S_{T}+D}{2} \quad \Rightarrow \quad \frac{S_{T}+D}{2}=\frac{0.02+0.01}{2}=0.015 \mathrm{~m}
$$

It can be seen that $S_{D}$ is greater than $\frac{S_{T}+D}{2}$, then the maximum velocity can be estimated by using $U_{\max }=\frac{S_{T}}{S_{T}-D} U_{\infty}$

Where $U_{\infty}$ is the free stream air inlet velocity $U_{\infty}=3.25 \mathrm{~m} / \mathrm{s}$

$$
U_{\max }=\frac{0.02}{0.02-0.01}(3.25)=6.5 \mathrm{~m} / \mathrm{s}
$$

The Reynolds number based on the maximum velocity is

$$
\operatorname{Re}_{D \max }=\frac{U_{\max } D}{v}
$$

Where $v$ is the fluid mean inlet viscosity and the Reynolds number is:

$$
\operatorname{Re}_{D \max }=\frac{(6.5)(0.01)}{16.81 \times 10^{-6}}=3867
$$




$$
\begin{gathered}
a=\frac{S_{T}}{D}=\frac{0.02}{0.01}=2 \\
b=\frac{S_{L}}{D}=\frac{0.02}{0.01}=2 \\
\frac{a}{b}=1
\end{gathered}
$$

From Figure 12, $f \approx 0.4$ and $\Phi \approx 1$ and $N_{L}=4$ (number of rows)

$$
\begin{aligned}
& \Delta P=N_{L} \Phi \frac{\rho_{m} U_{\max }^{2}}{2} f \\
& \Delta P=(4)(1) \frac{(1.097)(6.5)^{2}}{2}(0.4)
\end{aligned}
$$

The pressure drop of the heat exchanger is:

$$
\triangle P=37.1 P a
$$

\section{Interface suction velocity}

The interface suction velocity can be calculated by equation 3.67

$$
V_{i}=\frac{\dot{m}_{v}}{\rho_{m} A m_{i}}
$$

The condensation mass flow rate, $\dot{m}_{v}=3.055 \times 10^{-4} \mathrm{~kg} / \mathrm{s}$

The mass fraction of vapour at the interface, $m_{i}=9.308 \times 10^{-3}$

The mixture mean density, $\rho_{m}=1.097 \mathrm{~kg} / \mathrm{m}^{3}$

Area of the coil, $A=5.34 \times 10^{-2} \mathrm{~m}^{2}$

$$
V_{i}=\frac{3.055 \times 10^{-4}}{1.097\left(5.34 \times 10^{-2}\right)\left(9.308 \times 10^{-3}\right)}
$$




$$
V_{i}=0.56 \mathrm{~m} / \mathrm{s}
$$

The percentage of the suction velocity compare to the velocity of mixture is:

$$
\frac{V_{i}}{\bar{V}}(100)=\frac{0.56}{3.25}(100)=17.23 \%
$$

Hence the interfacial suction velocity is $17.23 \%$ of the free stream velocity. 


\title{
Appendix -B- Sample EES Calculation and Result
}

\author{
EES Converged Solutions for First Coil \\ Input \\ Unit Settings $[\mathrm{J}] /[\mathrm{C}] /[\mathrm{Pa}] /[\mathrm{kg}] /[$ degree $]$
}

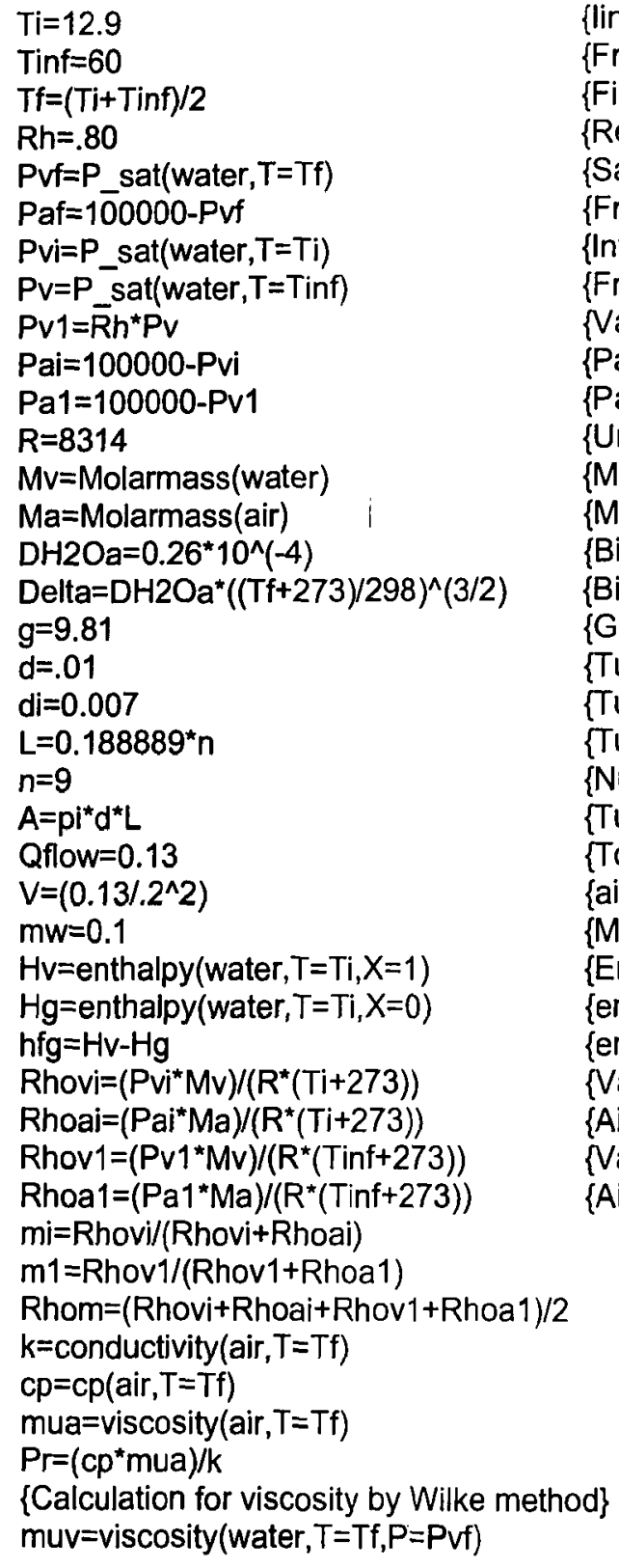

$\{$ Vapour viscosity at Tfilm\}

Phiav $=\left(1+(\mathrm{mua} / \mathrm{muv})^{\wedge}(0.5)^{\star}(\mathrm{Mv} / \mathrm{Ma})^{\wedge}(0.25)\right)^{\wedge} 2 /\left(4 / \mathrm{sqrt}(2)^{\star}(1+(\mathrm{Ma} / \mathrm{Mv}))^{\wedge} 0.5\right)\{$ Wilke equation Phi air/vapour\}

Phiva $=\left(1+(\text { muv } / \text { mua })^{\wedge}(0.5)^{\star}(\mathrm{Ma} / \mathrm{Mv})^{\wedge}(0.25)\right)^{\wedge} 2 /\left(4 / \mathrm{sqrt}(2)^{\star}(1+(\mathrm{Mv} / \mathrm{Ma}))^{\wedge} 0.5\right)$ \{Wilke equation Phi vapour/air\}

mum=muv/(1+(Paf/Pvf) ${ }^{*}$ Phiva $)+$ mua/(1+(Pvf/Paf $)^{*}$ Phiav $)\{$ Mixture viscosity for Wilke equation $\}$ 
\{Calculation for mass transfer\}

$\mathrm{Nu}=\mathrm{mum} / \mathrm{Rhom}$

$\mathrm{Sc}=\mathrm{Nu} / \mathrm{delta}$

Red $=\left(\right.$ Rhom $\left.^{*} V^{*} d\right) /$ mum

$\mathrm{C}=0.683$

$m=0.466$

$\mathrm{Sh}=\mathrm{C}^{\star} \operatorname{Red}^{\wedge} \mathrm{m}^{\star} \mathrm{Sc}^{\wedge}(1 / 3)$

$\mathrm{gm}=\left(\right.$ rhom $^{\star} \mathrm{Sh}^{\star}$ Delta $) / \mathrm{d}$

$m$ dotv $=A^{*} g^{\star}(m 1-m i)$

$\mathrm{ql}=\mathrm{hfg}^{\star} \mathrm{mdotv}^{*}$

Rmass $=($ Tinf-Ti $) / q l$

\{Calculation for sensible heat transfer\}

Nus $=C^{\star} \operatorname{Red}^{\wedge} m^{\star} \operatorname{Pr}^{\wedge}(1 / 3)$

hsen $=\left(N^{*} s^{*} k\right) / d$

Rsen $=1 /\left(\right.$ hsen $\left.{ }^{*} A\right)$

qsen $=($ Tinf-Ti)/Rsen

Rot $=((1 / \text { Rmass })+(1 / \text { Rsen }))^{\wedge}(-1)$

\{Calculation for condensation Heat Transfer\}

Ti-Ts=1.91

$\mathrm{Tsf}=(\mathrm{Ti}+\mathrm{Ts}) / 2$

Psf $=$ P_sat(water, $T=T s f)$

$k l=$ conductivity (water, $T=T s f, x=0)$

Mul=viscosity $($ water, $T=T s f, x=0)$

rho=density (water, $T=T s f, x=0$ )

Nucond $=0.729^{\star}\left(\left(g^{*} h f g^{\star} r h o^{\wedge} 2^{*}\left(n^{*} d\right)^{\wedge} 3\right) /\left(M u l^{*} k l^{*}(T i-T s)\right)\right)^{\wedge} .25$

hcond $=\left(\right.$ Nucond $\left.d^{*} \mathrm{KI}\right) /\left(\mathrm{n}^{*} \mathrm{~d}\right)$

\{Calculation for Internal Convection\}

Twi $=8$

Two $=10.14$

$T w f=(T w i+T w o) / 2$

$k w=$ conductivity $($ water, $T=T w f, x=0)$

$c p w=c p($ water $, T=T w f, x=0)$

rhow $=$ density $($ water, $T=T w f, x=0)$

muw $=$ viscosity $($ water $, T=T w f, x=0)$

$\mathrm{Prw}=\left(\mathrm{cpw} \mathrm{w}^{*} \mathrm{muw}\right) / \mathrm{kw}$

Redw $=\left(4^{*} \mathrm{mw}\right) /\left(\mathrm{pi}^{\star *} \mathrm{di}^{\star} \mathrm{muw}\right)$

Nui $=0.012^{\star}\left(\operatorname{Redw}^{\wedge}(0.87)-280\right)^{\star} \operatorname{Prw}^{\wedge}(0.4)$

$\mathrm{hi}=($ Nui*kw)/di

\{Overall heat transfer rate

$\mathrm{U}=\left(\left(\mathrm{A}^{*} \text { Rot }\right)+(1 / \text { hcond })+(1 / \mathrm{hi})\right)^{\wedge}(-1)$

Twon $=$ Tinf-(Tinf-Twi) $)^{\star} \operatorname{Exp}\left(-\left(U^{\star} A\right) /\left(0.1^{*} \mathrm{cpw}\right)\right)$

$\mathrm{Qt}=m w^{\star} \mathrm{cpw}^{\star}($ Twon-Twi)

Tin=Tinf-Q $t^{\star}$ Rot

$\mathrm{dTcn}_{\mathrm{T}} \mathrm{Qt} /\left(\right.$ hcond $\left.^{\star} \mathrm{A}\right)$
\{Kinematic Viscosity\}

\{Schmidt number\}

\{Reynolds number\}

\{Hilpert's Constant\}

\{Hilpert's constant\}

\{Sherwood number\}

\{Diffusion Coefficient\}

\{Mass flow rate of vapour\}

\{Heat flow rate (latent)\}

\{Mass transfer resistance\}

\{Nusselt number\}

\{Sensable heat coefficient\}

\{Sensable resistance\}

\{Sensible heat transfer rate\}

\{Rmass + Rsensable\}

\{Interface Temperature difference\}

\{Interfacial film temperature\}

\{Saturation pressure at interface film T\}

\{Conductivity of water at Tfilm interface\}

\{Viscosity of water at interface film T\}

\{Density of water at interface film T\}

\{Nusselt number condensation\}

Water inlet temperature

\{Water outlet temperature\}

$\{$ Water film temperature

\{Conductivity of water at water film\}

\{Heat capacity of water at water film\}

\{Density of water at water film T\}

$\{$ Viscosity of water at water film T\}

\{Prandtl number of water at Twf

\{Reynolds number of water\}

\{Nusseit number water\}

\{Heat transfer coefficient internalflow\}

\{Overall heat transfer coefficient\}

\{Water outlet temperature\}

\{Total heat transfer\}

\{New interface temperature\}

\{New, Ti-Ts\} 
Result for coil 1

Unit Settings $[\mathrm{J}] /[\mathrm{C}] /[\mathrm{Pa}] /[\mathrm{kg}] /[$ degree $]$

Variables in Main

$A=0.05341$

$\mathrm{C}=0.683$

$\mathrm{cp}=1007$

cpw $=4190$

$\mathrm{d}=0.01$

Delta $=0.00002751$

$\mathrm{DH} 2 \mathrm{Oa}=0.000026$

$\mathrm{di}=0.007$

$\mathrm{dTcn}=1.90$

$\mathrm{g}=9.81$

$\mathrm{gm}=0.05949$

hcond $=8798$

$\mathrm{hfg}=2.470 \mathrm{E}+06$

$\mathrm{Hg}=54129$

$\mathrm{hi}=8878$

hsen $=55.01$

$\mathrm{Hv}=2.524 \mathrm{E}+06$

$\mathrm{k}=0.02636$

$\mathrm{kl}=0.5711$

$\mathrm{kw}=0.5656$

$\mathrm{L}=1.7$

$\mathrm{m}=0.466$

$\mathrm{ml}=0.1055$

$\mathrm{Ma}=28.97$

maj $\times 0000305$

$\mathrm{mi}=0.009308$

mua $=0.00001902$

$\mathrm{Mul}=0.001237$

mum $=0.00001845$

muv $=0.0000102$

muw $=0.001342$

$\mathrm{Mv}=18.02$

$\mathrm{mw}=0.1$

$\mathrm{n}=9$

$\mathrm{Nu}=0.00001681$

Nucond $=1386$

Nui $=109.9$

Nus $=20.87$

$\mathrm{Pal}=84054$

$\mathrm{Paf}=93906$
Pai $=98512$

Phiav $=1.072$

Phiva $=0.9243$

$\mathrm{Pr}=0.7264$

Prw $=9.944$

Psf $=1398$

$\mathrm{Pv}=19932$

Pv1 $=15946$

Pvf $=6094$

Pvi $=1488$

Qflow $=0.13$

y 17552

qsen-1 38 .

(1) $t=894$

$\mathrm{R}=8314$

Red $=1933$

Redw $=13550$

Rhi $=8$

rho $=999.5$

Rhoal $=0.8794$

Rhoai=1.201

Rhom $=1.097$

Rhov1 $=0.1038$

Rhovi $=0.01128$

rhow $=1000$

Rmass $=0.06237$

Rot $=0.053$

Rsen $=0.3404$

$\mathrm{Sc}=0.6111$

$\mathrm{Sh}=19.7$

$\mathrm{Tf}=36.45$

$1=12.9$

Tinn

Tinf $=60.0$

$\mathrm{Ts}=10.99$

Tsf $=11.95$

Twf $=9.07$

Twi $=8$

Two $=10.14$

Twon=10.13

$\mathrm{U}=328.8$

$\mathrm{V}=3.25$ 


\section{After Coil Conditions for Coil 1 Input data}



$\{T w b=$ wetbulb(airh2o, $T=T x, W=W 2, P=P a t m)\}$

\{Atmospheric temperature\}

\{Guess temperature outlet\}

\{Interface temperature\}

\{Free stream temperature\}

\{Film temperature\}

\{Vapour saturated temperature at $\mathrm{Tf}\}$

\{Air pressure at Tf\}

\{Vapour partial pressure at Ti\}

\{Saturated pressure vapour at Tinf\}

\{apour partial pressure free stream\}

\{Partial pressure air at Ti\}

\{Partial pressure air at Tinf\}

\{Universal gas constant\}

\{Molecular weight of water\}

\{Molecular weight of air\}

\{Water outlet temperature\}

\{Moist air flowrate\}

\{mass flowrate of vapour\}

\{Enthalpy air at T guess\}

\{Enthalpy air at Tinf\}

\{Specific humidity at inlet\}

\{Mass flowrate of air\}
\{Specific Humidity outlet\} 


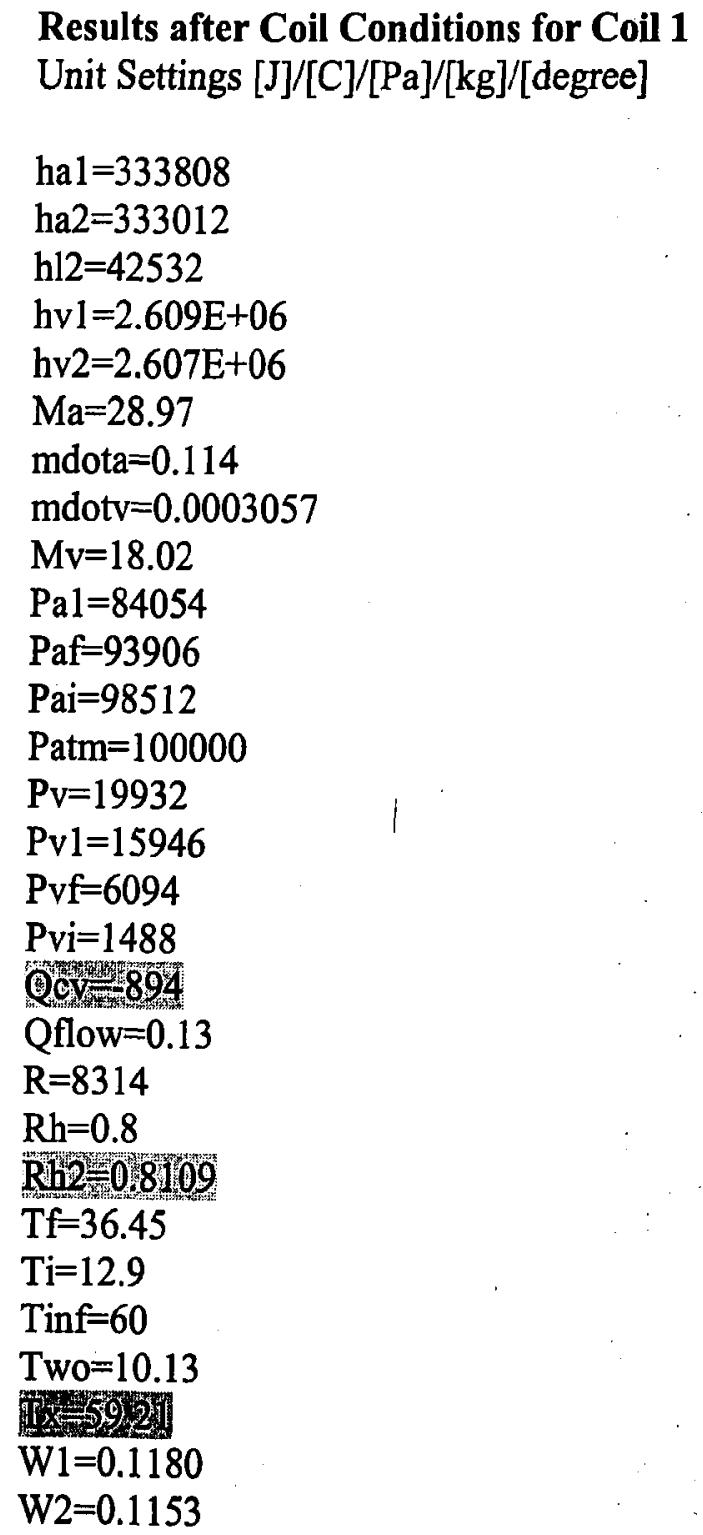




\section{EES Converged Solutions for Second Coil Unit Settings $[\mathrm{J}] /[\mathrm{C}] /[\mathrm{Pa}] /[\mathrm{kg}] /[$ degree $]$ \\ Input}

$\mathrm{Ti}=12.7$

Tinf $=59.21$

$\mathrm{Tf}=(\mathrm{Ti}+\mathrm{Tinf}) / 2$

$\mathrm{Rh}=.811$

$P v f=P$ sat $($ water,$T=T f)$

Paf $=100000-P$ vf

$P v i=P$ sat $($ water,$T=T i)$

$P v=P$ _sat(water, $T=T$ inf)

$P \vee 1=R h^{\star} P V$

Pai=100000-Pvi

$P a 1=100000-P v 1$

$\mathrm{R}=8314$

Mv=Molarmass(water)

Ma=Molarmass(air)

$\mathrm{DH} 2 \mathrm{Oa}=0.26^{\star} 10^{\wedge}(-4)$

Delta $=\mathrm{DH} 2 \mathrm{Oa}^{\star}((\mathrm{Tf}+273) / 298)^{\wedge}(3 / 2)$

$\mathrm{g}=9.81$

$\mathrm{d}=.01$

$\mathrm{di}=0.007$

$L=0.188889^{*} n$

$\mathrm{n}=9$

$A=p^{*} d^{*} L$

Qflow $=0.13$

$\mathrm{V}=\left(0.13 / .2^{\wedge} 2\right)$

$\mathrm{mw}=0.1$

$\mathrm{Hv}=$ enthalpy (water, $\mathrm{T}=\mathrm{Ti}, \mathrm{X}=1$ )

$\mathrm{Hg}=$ enthalpy (water, $\mathrm{T}=\mathrm{Ti}, \mathrm{X}=0$ )

hfg $=\mathrm{Hv}-\mathrm{Hg}$

Rhovi $=\left(\left.\mathrm{PVl}\right|^{*} \mathrm{Mv}\right) /\left(\mathrm{R}^{*}(\mathrm{Ti}+273)\right)$

Rhoai $=\left(\mathrm{Pai}^{*} \mathrm{Ma}\right) /\left(\mathrm{R}^{*}(\mathrm{Ti}+273)\right)$

Rhov1 $=\left(P \vee 1^{*} M v\right) /\left(R^{*}(\right.$ Tinf +273$\left.)\right)$

Rhoa1 $=\left(\mathrm{Pa1}{ }^{*} \mathrm{Ma}\right) /\left(\mathrm{R}^{*}\left(\mathrm{Tinf}^{2}+273\right)\right)$

mi=Rhovi/(Rhovi+Rhoai)

$\mathrm{m} 1=$ Rhov1/(Rhov1+Rhoa1)

Rhom $=($ Rhovi+Rhoai+Rhov1+Rhoa1 $) / 2$

$\mathrm{k}=$ conductivity (air, $\mathrm{T}=\mathrm{Tf}$ )

$\mathrm{cp}=\mathrm{cp}($ air, $\mathrm{T}=\mathrm{Tf}$ )

mua=viscosity(air, $T=T f$ )

$\mathrm{Pr}=\left(\mathrm{cp}^{\star} \mathrm{mua}\right) / \mathrm{k}$

\{Calculation for viscosity by Wilke method\}

muv=viscosity (water, $T=T f, P=P v f$ )

Phiav $=\left(1+(\text { mualmuv })^{\wedge}(0.5)^{\star}(\mathrm{Mv} / \mathrm{Ma})^{\wedge}(0.25)\right)^{\wedge} 2 /\left(4 / \mathrm{sqr}(2)^{\star}(1+(\mathrm{Ma} / \mathrm{Mv}))^{\wedge} 0.5\right)$

Phi air/vapour\}

Phiva $=\left(1+(\text { muv/mua })^{\wedge}(0.5)^{\star}(\mathrm{Ma} / \mathrm{Mv})^{\wedge}(0.25)\right)^{\wedge} 2 /\left(4 / \mathrm{sqr}(2)^{\star}(1+(\mathrm{Mv} / \mathrm{Ma}))^{\wedge} 0.5\right)$

Phi vapour/air\}

mum $=$ muv $/\left(1+(\text { Paf } / \text { Pvf })^{\star}\right.$ Phiva $)+$ mua $/\left(1+(\text { Pvf } / \text { Paf })^{\star}\right.$ Phiav $)$ equation\} \{linterfacial temperature\}

\{Free stream temperature\}

\{Film temperature\}

\{Relative Temperature\}

\{Saturated pressure at $T f$ \}

\{Free stream air temperature

\{Interface pressure at Ti\}

\{Free stream pressure at Tinf\}

$\{$ Vapour partial pressure at Tinf

\{Partial pressure of air at Ti\}

\{Partial pressure of air at Tinf\}

\{Universal gas constant\}

\{Molecular weight of water\}

\{Molecular weight of air\}

\{Binary Diffusion Coefficient @1atm. and 298 K\}

\{Binary Diffusion Coefficient @1atm. and Tf\}

\{Gravitaional constant\}

\{Tube Diameter\}

\{Tube internal diameter\}

\{Tube length $\}$

\{Number of Tube\}

\{Tube surface area\}

\{Total air flow rate\}

\{air velocity\}

\{Mass flowrate of water\}

\{Enthalpy of water vapour\}

\{enthalpy of liquid water\}

\{enthalpy of phase change\}

\{Vapour density at Ti\}

\{Air density at Ti\}

\{Vapour density at Tinf\}

\{Air density at Tinf\}

\{Mass friction of vapour at interface\}

\{Mass friction of vapour at free stream\}

\{Mixture mean density\}

\{Air conductivity at Tfilm\}

\{Capacity heat capacity at Tf\}

\{Air viscosity at Tfilm\}

\{Prandtl number\}

\{Vapour viscosity at Tfilm\}

$\{$ Wilke equation

WWilke equation

\{Mixture viscosity for Wilke 
\{Calculation for mass transfer\}

$\mathrm{Nu}=$ mum/Rhom

$\mathrm{Sc}=\mathrm{Nu} / \mathrm{delta}$

Red $=\left(\right.$ Rhom $\left.^{\star} V^{*} \mathrm{~d}\right) / \mathrm{mum}$

$\mathrm{C}=0.683$

$\mathrm{m}=0.466$

$\mathrm{Sh}=\mathrm{C}^{*} \operatorname{Red}^{\wedge} \mathrm{m}^{*} \mathrm{Sc}^{\wedge}(1 / 3)$

gm $=\left(\right.$ rhom $^{*} \mathrm{Sh}^{*}$ Delta $) / d$

mdotv $=A^{*} \mathrm{gm}^{*}(\mathrm{~m} 1-\mathrm{ml})$

$q$ l=hfg*mdotv

Rmass $=($ Tinf $-\mathrm{Ti}) / \mathrm{ql}$

\{Calculation for sensible heat transfer\}

Nus $=C^{\star} \operatorname{Red}{ }^{\wedge} m^{*} \operatorname{Pr}^{\wedge}(1 / 3)$

hsen $=\left(\right.$ Nus $\left.{ }^{*} k\right) / d$

Rsen $=1 /\left(\right.$ hsen ${ }^{*} A$ )

qsen $=($ Tinf-Ti)/Rsen

Rot $=((1 / \text { Rmass })+(1 / \text { Rsen }))^{\wedge}(-1)$

\{Calculation for condensation Heat Transfer\}

Ti-Ts=1.71

difference

$T s f=(T i+T s) / 2$

$P s f=P \_s a t(w a t e r, T=T s f)$

$\mathrm{kl}=$ conductivlty $($ water, $T=T s f, x=0)$

Mul=viscosity (water, $T=T s f, x=0)$

rho=density $($ water $, T=T s f, x=0)$

Nucond $=0.729^{\star}\left(\left(g^{*} h f g^{*} r h 0^{\wedge} 2^{*}\left(n^{*} d\right)^{\wedge} 3\right) /\left(M u l^{*} k l^{*}(T i-T s)\right)\right)^{\wedge} .25$

hcond $=\left(\right.$ Nucond $\left.d^{\star} \mathrm{KI}\right) /\left(\mathrm{n}^{\star} \mathrm{d}\right)$

\{Calculation for Internal Convection\}

Twi $=8$

Two $=9.86$

$\mathrm{Twf}=(\mathrm{Twi}+\mathrm{Two}) / 2$

$k w=$ conductivity $($ water, $T=T w f, x=0)$

$c p w=c p($ water $, T=T w f, x=0)$

rhow $=$ density $($ water, $T=T w f, x=0)$

muw $=$ viscosity (water, $T=T w f, x=0)$

$\operatorname{Prw}=\left(\mathrm{cpw}^{*} \mathrm{muw}\right) / \mathrm{kw}$

$\operatorname{Redw}=\left(4^{*} \mathrm{mw}\right) /\left(\mathrm{pi}^{*} \mathrm{di}^{*} \mathrm{muw}\right)$

Nui $=0.012^{\star}\left(\operatorname{Red} w^{\wedge}(0.87)-280\right)^{\star} \operatorname{Prw}^{\wedge}(0.4)$

$\mathrm{hi}=\left(\mathrm{Nui}{ }^{*} \mathrm{kw}\right) / \mathrm{di}$

\{Overall heat transfer rate\}

$U=\left(\left(A^{*} R o t\right)+(1 / \text { hcond })+(1 / h \mathrm{l})\right)^{\wedge}(-1)$

Twon $=$ Tinf $-(\text { Tinf-Twi })^{\star} \operatorname{Exp}\left(-\left(\mathrm{U}^{*} \mathrm{~A}\right) /\left(0.1^{*} \mathrm{cpw}\right)\right)$

$Q t=m w^{*} c p w^{*}(T w o n-T w i)$

Tin=Tinf-Qt*Rot

dTcn $=Q t /\left(\right.$ hcond $\left.{ }^{*} A\right)$
\{Kinematic Viscosity\}

\{Schmidt number\}

\{Reynolds number\}

\{Hilpert's Constant\}

\{Hilpert's constant\}

\{Sherwood number\}

\{Diffusion Coefficient\}

\{Mass flow rate of vapour\}

\{Heat flow rate (latent)\}

\{Mass transfer resistance\}

\{Nusselt number\}

\{Sensable heat coefficient\}

\{Sensable resistance\}

\{Sensible heat transfer rate\}

$\{$ Rmass + Rsensable $\}$

\{lnterface Temperature

\{Interfacial film temperature

\{Saturation pressure at interface film T\}

\{Conductivity of water at Tfilm interface\}

\{Viscosity of water at interface film T\}

\{Density of water at interface film T\}

$.25 \quad$ Nusselt number condensation\}

\{Condensation heat transfer coefficient\}

$\{$ Water inlet temperature $\}$

\{Water outlet temperature\}

\{Water film temperature\}

\{Conductivity of water at water film\}

\{Heat capacity of water at water film\}

\{Density of water at water film T\}

$\{$ Viscosity of water at water film T\}

\{Prandtl number of water at Twf\}

\{Reynolds number of water\}

\{Nusselt number water\}

$\{$ Heat transfer coefficient internalflow\}

\{Overall heat transfer coefficient\}

\{Water outlet temperature\}

\{Total heat transfer\}

\{New interface temperature

\{New, Ti-Ts $\}$ 
EES Results for Coil 2

Unit Settings

$[\mathrm{J}] /[\mathrm{C}] /[\mathrm{Pa}] /[\mathrm{kg}] /[$ degree $]$

$\mathrm{A}=0.05341$
$\mathrm{C}=0.683$
$\mathrm{cp}=1007$
$\mathrm{cpw}=4190$
$\mathrm{~d}=0.01$
Delta $=0.00002745$
$\mathrm{DH} 2 \mathrm{Oa}=0.000026$
$\mathrm{di}=0.007$
$\mathrm{dTcn}=1.81$
$\mathrm{~g}=9.81$
$\mathrm{gm}=0.05954$
$\mathrm{hcond}=9037$
$\mathrm{hfg}=2.471 \mathrm{E}+06$
$\mathrm{Hg}=53292$
$\mathrm{hi}=8856$
$\mathrm{hsen}=55.01$
$\mathrm{Hv}=2.524 \mathrm{E}+06$
$\mathrm{k}=0.02632$
$\mathrm{kl}=0.571$
$\mathrm{kw}=0.5653$
$\mathrm{~L}=1.7$
$\mathrm{~m}=0.466$
$\mathrm{~m} 1=0.103$
$\mathrm{Ma}=28.97$
$\mathrm{md} \mathrm{m}+\mathrm{m}=0.0002983$
$\mathrm{mi}=0.009186$
$\mathrm{mua}=0.000019$
$\mathrm{Mul}=0.00124$
$\mathrm{mum}=0.00001844$
$\mathrm{muv}=0.00001019$
$\mathrm{muw}=0.001348$
$\mathrm{Mv}=18.02$
$\mathrm{mw}=0.1$
$\mathrm{n}=9$
$\mathrm{Nu}=0.00001677$
$\mathrm{Nucond}=1424$
$\mathrm{Nui}=109.7$
$\mathrm{Nus}=20.9$
$\mathrm{~Pa} 1=84417$

$\mathrm{Paf}=94069$

Phiva $=0.9242$

$\mathrm{Pr}=0.7266$

Prw=9.99

Psf $=1388$

$\mathrm{Pv}=19215$

Pvl $=15583$

$\mathrm{Pvf}=5931$

Pvi=1469

Qflow $=0.13$

$\mathrm{ql}=736.9$

qsen $=136.6$

$\mathrm{Q} t=873$

$\mathrm{R}=8314$

Red $=1938$

Redw $=13494$

$\mathrm{Rh}=0.811$

rho $=999.5$

Rhoal $=0.8853$

Rhoai $=1.202$

Rhom $=1.1$

Rhovl $=0.1016$

Rhovi $=0.01114$

rhow $=1000$

Rmass $=0.06311$

Rot $=0.053$

Rsen $=0.3404$

$\mathrm{Sc}=0.611$

$\mathrm{Sh}=19.72$

$\mathrm{Tf}=35.96$

$\mathrm{Ti}=12,7$

$\operatorname{Tin}=12.7$

Tinf $=59.2$

Ts $=10.99$

Tsf $=11.85$

Twf $=8.93$

Twi $=8$

Two $=9.86$

Twon=10.08

$\mathrm{U}=326$

$\mathrm{V}=3.25$ 
After Coll Conditions for coll 2

Unit Settings $[\mathrm{J}] /[\mathrm{C}] /[\mathrm{Pa}] /[\mathrm{kg}] /[$ degree $]$

\{lnput data\}

Patm $=100000$

$T x=58.43$

$\mathrm{Ti}=12.7$

Tinf $=59.21$

$T f=(T i+T i n f) / 2$

$\mathrm{Rh}=.811$

$P v f=P \_s a t(w a t e r, T=T f)$

$P a f=100000-P v f$

$P v i=P$ sat(water, $T=T i)$

$P v=P$ sat(water, $T=T$ Tinf)

$\mathrm{Pv} 1=\overline{\mathrm{R}} \mathrm{h}^{\star} \mathrm{PV}$

$P a i=100000-P v i$

$P a 1=100000-P v 1$

$\mathrm{R}=8314$

$M v=$ Molarmass(water)

$\mathrm{Ma}=$ Molarmass(air)

Two $=9.86$

Qflow $=0.13$

mdotv $=0.0002983$

hv1 $=$ enthalpy (water, $T=\operatorname{Tinf}, x=1$ )

hv2 $=$ enthalpy(water, $T=T x, x=1)$

hl2 $=$ enthalpy $($ water, $T=T$ wo,$x=0)$

ha1 =enthaipy (air, $T=T$ inf $)$

ha2 $=$ enthalpy $(\operatorname{air}, T=T x)$

\{Output\}

W1 $=0.622^{*}$ (Pv1/Pa1)

mdota $=\left(\mathrm{Pa} 1^{*} \mathrm{Ma}\right) /\left(\mathrm{R}^{*}(\operatorname{Tinf}+273)\right)^{*} \mathrm{Qflow}$

$\mathrm{W} 2=\mathrm{W} 1-(\mathrm{mdot} / \mathrm{mdota})$

\{lterative solution method to get the coil exit temperature\}

Qcv=mdota*((ha2-ha1)-W1*hv1+W2*hv2+(W1-W2 $)^{\star}$ hl2) $\{775$ W $\}$

Rh2=Reihum(airh2o, $T=T x, W=W 2, P=P a t m$ )

$\{T w b=$ wetbulb(airh2o, $T=T x, W=W 2, P=P a t m)\}$

Tdp=dewpoint(airh2o, $T=T x, W=W 2, P=P$ atm)

haf $=$ enthalpy(airh2o, $T=T x, W=W 2, P=P a t m$ )

$\{$ hrw=humrat(airh2o, $T=T x, W=W 2, P=P a t m)$ \} 


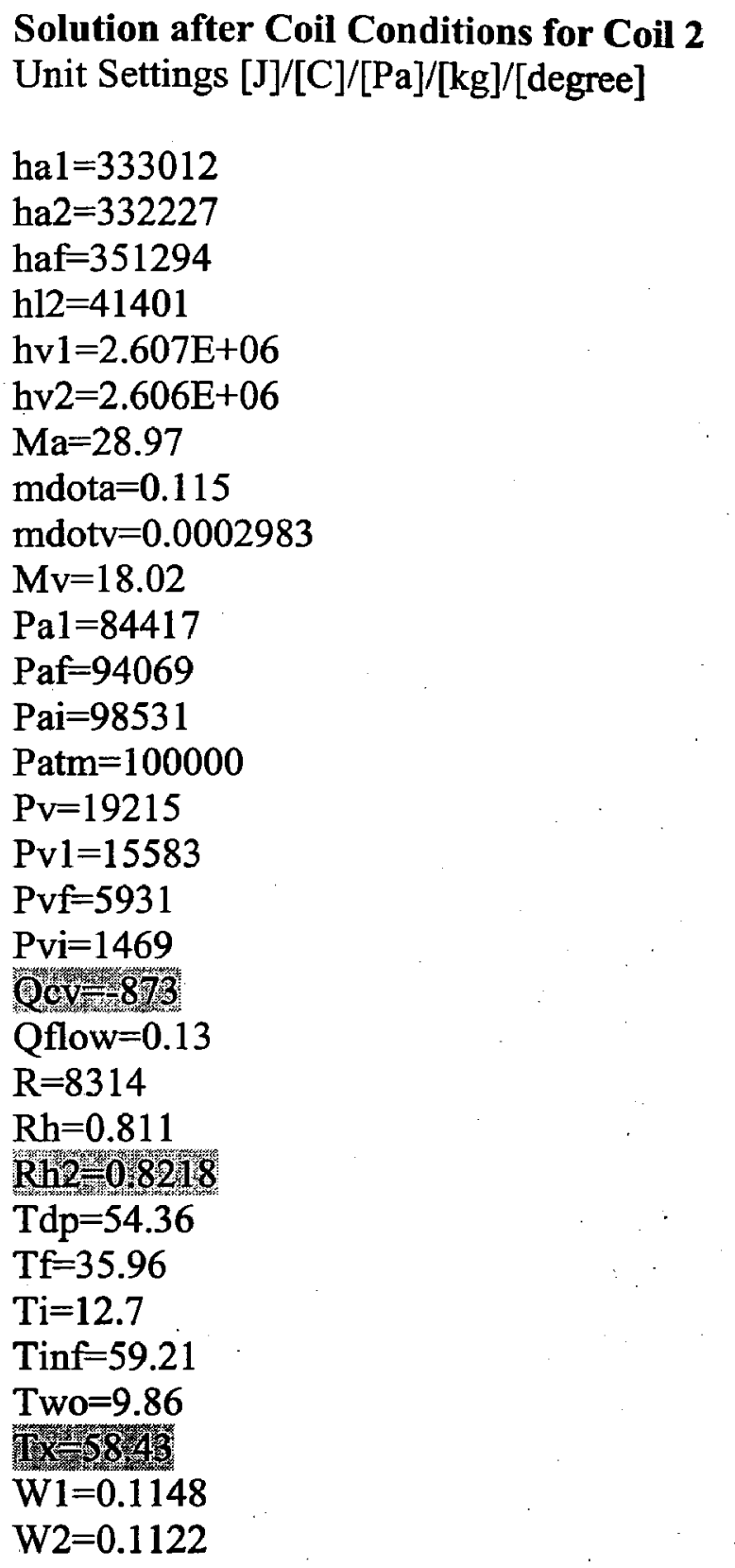




\section{EES Converged Solutions for Third Coll Unit Settings $[\mathrm{J}] /[\mathrm{C}] /[\mathrm{Pa}] /[\mathrm{kg}] /[$ degree $]$}

\section{Input}

$\mathrm{Ti}=12.6$

Tinf $=58.43$

$\mathrm{Tf}=(\mathrm{Ti}+\mathrm{Tinf}) / 2$

$\mathrm{Rh}=.8218$

$\mathrm{Pvf}=\mathrm{P}$ sat(water, $\mathrm{T}=\mathrm{Tf})$

Paf $=100000-P v f$

$P v i=P$ sat(water, $T=T i)$

$P v=P$ sat(water, $T=T$ inf)

$\mathrm{PV} 1=\overline{\mathrm{R}} \mathrm{N}^{*} \mathrm{PV}$

Pai $=100000-P v i$

$\mathrm{Pa} 1=100000-\mathrm{Pv} 1$

$\mathrm{R}=8314$

$\mathrm{Mv}=$ Molarmass(water)

Ma=Molarmass(air)

$\mathrm{DH} 2 \mathrm{Oa}=0.26^{\star} 10^{\wedge}(-4)$

Delta $=\mathrm{DH} 2 \mathrm{Oa}^{*}((\mathrm{Tf}+273) / 298)^{\wedge}(3 / 2)$

$g=9.81$

$d=.01$

$\mathrm{di}=0.007$

$L=0.188889^{*} n$

$\mathrm{n}=9$

$A=p i^{*} d^{*} L$

Qflow $=0.13$

$\mathrm{V}=\left(0.13 / .2^{\wedge} 2\right)$

$\mathrm{mw}=0.1$

$\mathrm{Hv}=$ enthalpy (water, $\mathrm{T}=\mathrm{Ti}, \mathrm{X}=1$ )

$\mathrm{Hg}=$ enthalpy (water, $\mathrm{T}=\mathrm{Ti}, \mathrm{X}=0$ )

$\mathrm{hfg}=\mathrm{Hv}-\mathrm{Hg}$

Rhovi $=\left(\mathrm{Pvi}^{*} \mathrm{Mv}\right) /\left(\mathrm{R}^{*}(\mathrm{Ti}+273)\right)$

Rhoai $=\left(\mathrm{Pai}^{*} \mathrm{Ma}\right) /\left(\mathrm{R}^{*}(\mathrm{Ti}+273)\right)$

Rhov1 $=\left(\mathrm{Pv} 1{ }^{*} \mathrm{Mv}\right) /\left(\mathrm{R}^{*}\left(\mathrm{Tinf}^{2}+273\right)\right)$

Rhoa1 $=(\mathrm{Pa}$ 1*Ma $) /\left(\mathrm{R}^{\star}(\operatorname{Tinf}+273)\right)$

$\mathrm{mi}=$ Rhovi/(Rhovi+Rhoai)

$\mathrm{m} 1=$ Rhov1/(Rhov1+Rhoa1)

Rhom=(Rhovi+Rhoai+Rhov1+Rhoa1)/2

$k=$ conductivity(air, $T=T f$ )

$c p=c p$ (air, $T=T f$ )

mua $=$ viscosity (air, $T=T f)$

$\mathrm{Pr}=\left(\mathrm{cp}^{*}\right.$ mua $) / \mathrm{k}$

\{Calculation for viscosity by Wilke method\}

muv=viscosity (water, $T=T f, P=P v f)$

Phiav $=\left(1+(\text { mua/muv })^{\wedge}(0.5)^{\star}(\mathrm{Mv} / \mathrm{Ma})^{\wedge}(0.25)\right)^{\wedge} 2 /\left(4 / \mathrm{sqrt}(2)^{\star}(1+(\mathrm{Ma} / \mathrm{Mv}))^{\wedge} 0.5\right)$

Phi air/vapour\}

Phiva $=\left(1+(\text { muv/mua })^{\wedge}(0.5)^{\star}(\mathrm{Ma} / \mathrm{Mv})^{\wedge}(0.25)\right)^{\wedge} 2 /\left(4 / \mathrm{sqrt}(2)^{\star}(1+(\mathrm{Mv} / \mathrm{Ma}))^{\wedge} 0.5\right)$

Phi vapour/air\}

mum=muv/(1+(Paf/Pvf)*Phiva)+mua/(1+(Pvf/Paf) $)^{*}$ Phiav $)$ equation $\}$ \{linterfacial temperature\}

\{Free stream temperature\}

\{Film temperature\}

\{Relative Temperature\}

\{Saturated pressure at Tf\}

\{Free stream air temperature\}

\{Interface pressure at Ti\}

\{Free stream pressure at Tinf\}

\{Vapour partial pressure at Tinf\}

\{Partial pressure of air at Ti\}

\{Partial pressure of air at Tinf\}

\{Universal gas constant\}

\{Molecular weight of water\}

\{Molecular weight of air\}

\{Binary Diffusion Coefficient @1atm. and 298 K\}

\{Binary Diffusion Coefficient @1atm. and Tf\}

\{Gravitaional constant\}

\{Tube Diameter\}

\{Tube internal diameter\}

\{Tube length\}

\{Number of Tube

\{Tube surface area\}

\{Total air flow rate\}

\{air velocity\}

\{Mass flowrate of water\}

\{Enthalpy of water vapour\}

\{enthalpy of liquid water\}

\{enthalpy of phase change\}

\{Vapour density at Ti\}

\{Air density at Ti\}

\{Vapour density at Tinf\}

\{Air density at Tinf\}

\{Mass friction of vapour at interface\}

[Mass friction of vapour at free stream\}

\{Mixture mean density\}

\{Air conductivity at Tfilm\}

\{Capacity heat capacity at $T$ \}

\{Air viscosity at Tfilm\}

\{Prandtl number\}

\{Vapour viscosity at Tfilm\}

$\{$ Wilke equation

Wilke equation

\{Mixture viscosity for Wilke 
\{Calculation for mass transfer\}

$\mathrm{Nu}=\mathrm{mum} / \mathrm{Rhom}$

$\mathrm{Sc}=\mathrm{Nu} /$ delta

Red $=\left(\right.$ Rhom $\left.V^{*} d\right) /$ mum

$\mathrm{C}=0.683$

$\mathrm{m}=0.466$

$\mathrm{Sh}=\mathrm{C}^{\star} \operatorname{Red}^{\wedge} \mathrm{m}^{\star} \mathrm{Sc}^{\wedge}(1 / 3)$

$\mathrm{gm}=($ rhom*Sh*Delta $) / \mathrm{d}$

mdotv $=A^{*} \mathrm{gm}^{*}(\mathrm{~m} 1-\mathrm{mi})$

ql=hfg ${ }^{*}$ mdotv

Rmass $=($ Tinf-Ti $) / q$ l

\{Calculation for sensible heat transfer\}

Nus $=C^{*} \operatorname{Red}^{\wedge} m^{*} \operatorname{Pr}^{\wedge}(1 / 3)$

hsen $=\left(\right.$ Nus $\left.^{*} k\right) / d$

Rsen $=1 /\left(\right.$ hsen $\left.^{*} A\right)$

qsen $=($ Tinf-Ti)/Rsen

Rot= $((1 / \text { Rmass })+(1 / \text { Rsen }))^{\wedge}(-1)$

\{Calculation for condensation Heat Transfer\}

Ti-Ts=1.78

$\mathrm{Tsf}=(\mathrm{Ti}+\mathrm{Ts}) / 2$

Psf=P_sat(water, $T=T s f)$

film $T\}$

$\mathrm{kl}=$ conductivity (water, $\mathrm{T}=\mathrm{Tsf}, \mathrm{x}=0$ )

Mul=viscosity (water, $T=T s f, x=0)$

\{Kinematic Viscosity\}

\{Schmidt number\}

\{Reynolds number\}

\{Hilpert's Constant\}

\{Hilpert's constant\}

\{Sherwood number\}

\{Diffusion Coefficient\}

\{Mass flow rate of vapour\}

\{Heat flow rate (latent)\}

\{Mass transfer resistance\}

\{Nusselt number\}

\{Sensable heat coefficient\}

\{Sensable resistance\}

\{Sensible heat transfer rate\}

rho $=\operatorname{density}($ water, $T=T s f, x=0)$

\{Rmass + Rsensable $\}$

\{Interface Temperature difference\}

\{Interfacial film temperature\}

\{Saturation pressure at interface

\{Conductivity of water at Tfilm interface\}

\{Viscosity of water at interface fiim T\}

\{Density of water at interface fiim T\}

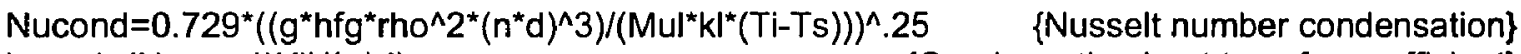

hcond $=\left(\right.$ Nucond $\left.d^{\star} \mathrm{KI}\right) /\left(\mathrm{n}^{\star} \mathrm{d}\right)$

\{Calculation for Internal Convection\}

\{Condensation heat transfer coefficient\}

Twi $=8$

Two $=10.03$

$\mathrm{Twf}=(\mathrm{Tw}+\mathrm{Two}) / 2$

$k w=$ conductivity (water, $T=T w f, x=0$ )

$\mathrm{cpw}=\mathrm{cp}($ water $, \mathrm{T}=\mathrm{Twf}, \mathrm{x}=0)$

rhow $=$ density $($ water, $T=T w f, x=0)$

muw $=$ viscosity (water, $T=T w f, x=0)$

Prw $=\left(c p w^{*}\right.$ muw $) / k w$

Redw $=\left(4^{*} \mathrm{mw}\right) /\left(\mathrm{pi}^{*} \mathrm{di}^{\star} \mathrm{muw}\right)$

Nui $=0.012^{\star}\left(\operatorname{Redw}^{\wedge}(0.87)-280\right)^{\star} \operatorname{Prw}^{\wedge}(0.4)$

$\mathrm{hi}=\left(\mathrm{Nui}{ }^{*} \mathrm{kw}\right) / \mathrm{di}$

\{Overall heat transfer rate

$U=\left(\left(A^{\star} \text { Rot }\right)+(1 / \text { hcond })+(1 / \text { hi })\right)^{\wedge}(-1)$

Twon=Tinf-(Tinf-Twi)*Exp $\left(-\left(U^{*} A\right) /\left(0.1^{*} \mathrm{cpw}\right)\right)$

$\{$ Water inlet temperature $\}$

$\{$ Water outlet temperature $\}$

$\{$ Water film temperature

\{Conductivity of water at water film\}

\{Heat capacity of water at water film\}

$\{$ Density of water at water film $\mathrm{T}\}$

$\{$ Viscosity of water at water film T\}

\{Prandtl number of water at Tw'\}

\{Reynolds number of water\}

\{Nusselt number water\}

$\{$ Heat transfer coefficient internalflow\}

$Q t=m w^{*} c p w^{*}(T w o n-T w i)$

Tin=Tinf-Qt* ${ }^{\star}$ Rot

dTcn $=Q t /\left(\right.$ hcond $\left.^{*} A\right)$

\{Overall heat transfer coefficient\}

\{Water outlet temperature\}

\{Total heat transfer\}

\{New interface temperature

\{New, Ti-Ts\} 


\section{Results for Coil 3}

\begin{tabular}{|c|c|}
\hline $\mathrm{A}=0.05341$ & Phiva $=0.9241$ \\
\hline$C=0.683$ & $\operatorname{Pr}=0.7267$ \\
\hline $\mathrm{cp}=1007$ & Prw $=9.962$ \\
\hline $\mathrm{cpw}=4190$ & Psf $=1376$ \\
\hline$d=0.01$ & $\mathrm{Pv}=18528$ \\
\hline Delta $=0.00002739$ & Pvl=15227 \\
\hline $\mathrm{DH} 2 \mathrm{Oa}=0.000026$ & $\mathrm{Pvf}=5789$ \\
\hline $\mathrm{di}=0.007$ & Pvi=1459 \\
\hline $\mathrm{dTcn}=1.79$ & Qflow $=0.13$ \\
\hline $\mathrm{g}=9.81$ & 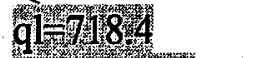 \\
\hline $\mathrm{gm}=0.05959$ & $9 \operatorname{sen}=1346$ \\
\hline hcond $=8935$ & (1) 853 \\
\hline$h f g=2.471 E+06$ & $\mathrm{R}=8314$ \\
\hline $\mathrm{Hg}=52873$ & Red $=1942$ \\
\hline $\mathrm{hi}=8870$ & $R e d w=13528$ \\
\hline hsen $=55$ & $\mathrm{Rh}=0.8218$ \\
\hline $\mathrm{Hv}=2.524 \mathrm{E}+06$ & rho $=999.5$ \\
\hline$k=0.02629$ & Rhoa1 $=0.8912$ \\
\hline $\mathrm{kl}=0.5707$ & Rhoai=1.202 \\
\hline $\mathrm{kw}=0.5655$ & Rhom=1.102 \\
\hline $\mathrm{L}=1.7$ & Rhovl $=0.09955$ \\
\hline $\mathrm{m}=0.466$ & Rhovi $=0.01107$ \\
\hline $\mathrm{ml}=0.1005$ & rhow $=1000$ \\
\hline $\mathrm{Ma}=28.97$ & Rmass $=0.0638$ \\
\hline mdotv $=0002907$ & Rot $=0.054$ \\
\hline $\mathrm{mi}=0.009125$ & Rsen $=0.3404$ \\
\hline mua $=0.00001898$ & $\mathrm{Sc}=0.6109$ \\
\hline $\mathrm{Mul}=0.001245$ & $\mathrm{Sh}=19.74$ \\
\hline mum $=0.00001844$ & $\mathrm{Tf}=35.52$ \\
\hline muv $=0.00001017$ & 72.6 \\
\hline $\mathrm{muw}=0.001345$ & $\operatorname{tin}=12: 6$ \\
\hline $\mathrm{Mv}=18.02$ & Tinf $=58.4$ \\
\hline $\mathrm{mw}=0.1$ & $\mathrm{Ts}=10.82$ \\
\hline$n=9$ & Tsf $=11.71$ \\
\hline $\mathrm{Nu}=0.00001673$ & Twf $=9.015$ \\
\hline Nucond=1409 & Twi $=8$ \\
\hline Nui= $=109.8$ & Two $=10.03$ \\
\hline Nus $=20.92$ & Twon $=10.04$ \\
\hline $\mathrm{Pa} 1=84773$ & $\mathrm{U}=323.2$ \\
\hline$P a f=94211$ & $\mathrm{~V}=3.25$ \\
\hline Pai=98541 & \\
\hline Phiav $=1.072$ & \\
\hline
\end{tabular}




\section{EES Solution after Coil Conditions for Third coil}

\{lnput data\}

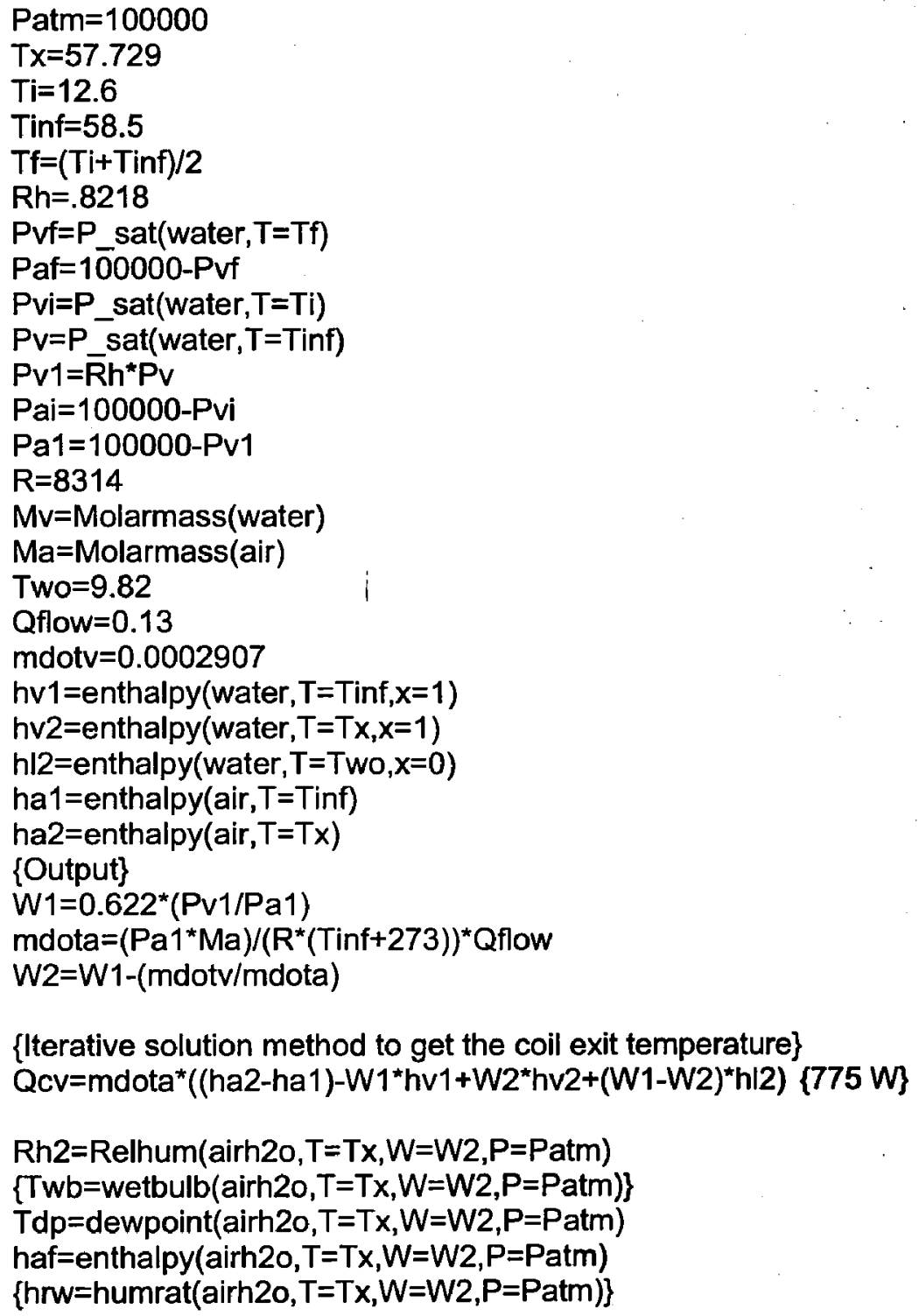




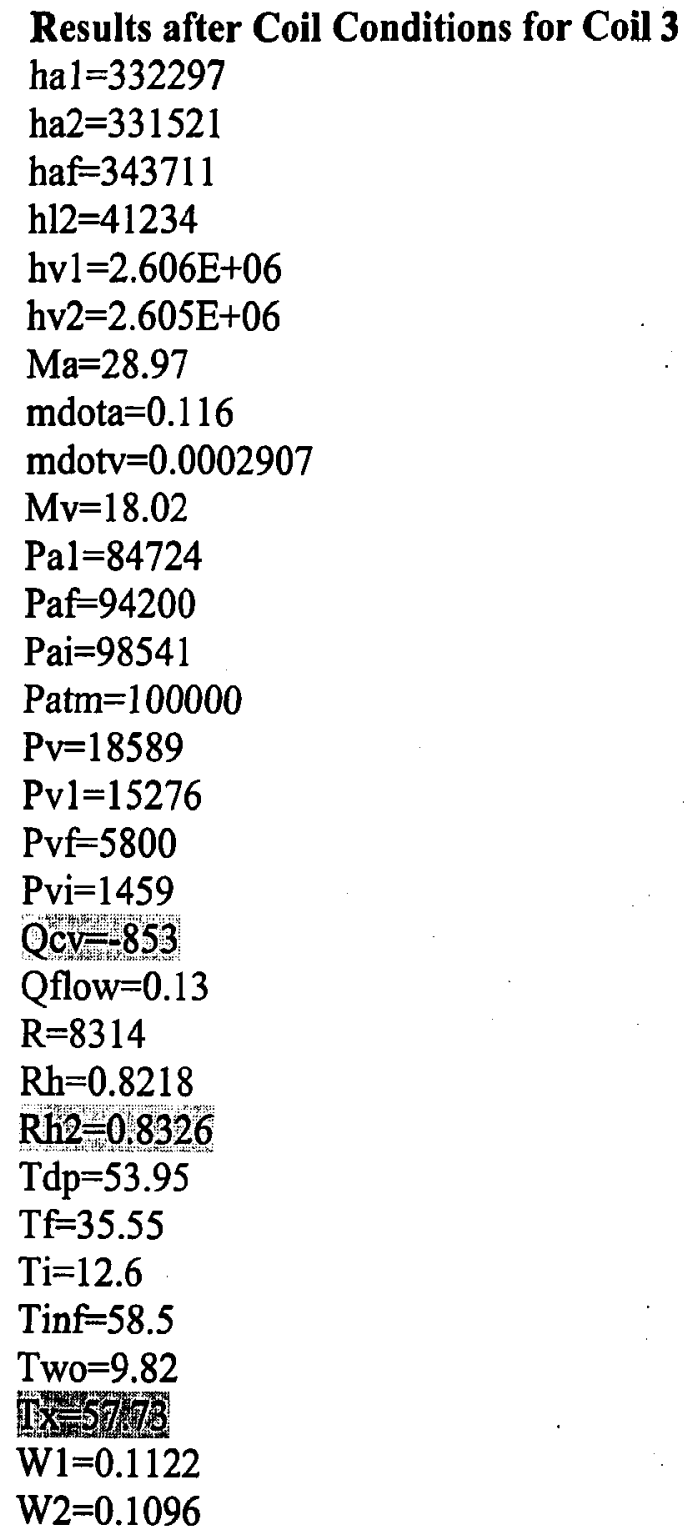




\section{EES Converged Solutions for Fourth Coil Unit Settings $[\mathrm{J}] /[\mathrm{C}] /[\mathrm{Pa}] /[\mathrm{kg}] /[$ degree $]$ Input}

$\mathrm{Ti}=12.5$

Tinf $=57.73$

$\mathrm{Tf}=(\mathrm{Ti}+\mathrm{Tinf}) / 2$

$\mathrm{Rh}=.8326$

Pvf=P_sat(water, $T=T f)$

$P a f=100000-P v f$

$\mathrm{Pvi}=\mathrm{P}$ sat $($ water, $\mathrm{T}=\mathrm{Ti}$ )

$P V=P$ sat (water, $T=T$ inf)

$\mathrm{PV} 1=\overline{\mathrm{R}} h^{\star} \mathrm{PV}$

Pai $=100000-P v i$

$\mathrm{Pa} 1=100000-\mathrm{Pv} 1$

$\mathrm{R}=8314$

$\mathrm{Mv}=$ Molarmass(water)

Ma=Molarmass(air)

$\mathrm{DH} 2 \mathrm{Oa}=0.26^{*} 10^{\wedge}(-4)$

Delta=DH2Oa* $((\mathrm{Tf}+273) / 298)^{\wedge}(3 / 2)$

$g=9.81$

$d=.01$

$\mathrm{di}=0.007$

$L=0.188889^{*} n$

$\mathrm{n}=\mathbf{9}$

$A=p^{*}{ }^{*}{ }^{*} L$

Qflow $=0.13$

$\mathrm{V}=\left(0.13 / .2^{\wedge} 2\right)$

$\mathrm{mw}=0.1$

$\mathrm{Hv}=$ enthalpy(water, $\mathrm{T}=\mathrm{Ti}, \mathrm{X}=1$ )

$\mathrm{Hg}=$ enthalpy (water, $\mathrm{T}=\mathrm{Ti}, \mathrm{X}=0$ )

$\mathrm{hfg}=\mathrm{Hv}-\mathrm{Hg}$

Rhovi $=\left(\mathrm{Pvi}^{\star} \mathrm{Mv}\right) /\left(\mathrm{R}^{*}(\mathrm{Ti}+273)\right)$

Rhoai $=\left(\mathrm{Pai}^{*} \mathrm{Ma}\right) /\left(\mathrm{R}^{*}(\mathrm{Ti}+273)\right)$

Rhov1 $=\left(P \vee 1^{*} M v\right) /\left(R^{*}(\operatorname{Tinf}+273)\right)$

Rhoa1 $=(P a 1 * M a) /\left(R^{*}(\operatorname{Tinf}+273)\right)$

mi=Rhovi/(RhovitRhoai)

$\mathrm{m} 1=$ Rhov1/(Rhov1+Rhoa1)

Rhom $=($ Rhovi + Rhoait + Rhov1 + Rhoa1 $) / 2$

$k=$ conductivity(air, $T=T f$ )

$\mathrm{cp}=\mathrm{cp}$ (air, $\mathrm{T}=\mathrm{Tf}$ )

mua=viscosity $($ air, $T=T f)$

$\mathrm{Pr}=\left(\mathrm{cp}^{*} \mathrm{mua}\right) / \mathrm{k}$

\{Calculation for viscosity by Wilke method\}

muv=viscosity $($ water $, T=T f, P=P v f)$ \{linterfacial temperature\}

\{Free stream temperature\}

\{Film temperature\}

\{Relative Temperature\}

\{Saturated pressure at Tf\}

\{Free stream air temperature\}

\{Interface pressure at Ti\}

\{Free stream pressure at Tinf\}

\{Vapour partial pressure at Tinf\}

\{Partial pressure of air at Ti\}

\{Partial pressure of air at Tinf\}

\{Universal gas constant\}

\{Molecular weight of water\}

\{Molecular weight of air\}

\{Binary Diffusion Coefficient @1atm. and 298 K\}

\{Binary Diffusion Coefficient @1atm. and Tf\}

\{Gravitaional constant\}

\{Tube Diameter\}

\{Tube internal diameter\}

\{Tube length\}

\{Number of Tube\}

\{Tube surface area\}

\{Total air flow rate\}

\{air velocity\}

\{Mass flowrate of water\}

\{Enthalpy of water vapour\}

\{enthalpy of liquid water\}

\{enthalpy of phase change\}

\{Vapour density at Ti\}

\{Air density at Ti\}

\{Vapour density at Tinf

\{Air density at Tinf\}

\{Mass friction of vapour at interface\}

\{Mass friction of vapour at free stream\}

\{Mixture mean density\}

\{Air conductivity at Tfilm\}

\{Capacity heat capacity at Tf\}

\{Air viscosity at Tfilm\}

\{Prandtl number\}

Phiav $=\left(1+(\mathrm{mua} / \mathrm{muv})^{\wedge}(0.5)^{\star}(\mathrm{Mv} / \mathrm{Ma})^{\wedge}(0.25)\right)^{\wedge} 2 /\left(4 / \mathrm{sqrt}(2)^{\star}(1+(\mathrm{Ma} / \mathrm{Mv}))^{\wedge} 0.5\right) \quad$ \{Wilke equation

Phi air/vapour\}

Phiva $=\left(1+(\text { muv } / \text { mua })^{\wedge}(0.5)^{\star}(\mathrm{Ma} / \mathrm{Mv})^{\wedge}(0.25)\right)^{\wedge} 2 /\left(4 / \mathrm{sqrt}(2)^{\star}(1+(\mathrm{Mv} / \mathrm{Ma}))^{\wedge} 0.5\right) \quad$ [Wilke equation

Phi vapour/air\}

mum $=$ muv $/\left(1+(\text { Paf } / \text { Pvf })^{\star}\right.$ Phiva $)+$ mual $/\left(1+(P v f / P a f)^{\star}\right.$ Phiav $)$

\{Mixture viscosity for Wilke

equation\}

\{Calculation for mass transfer\} 


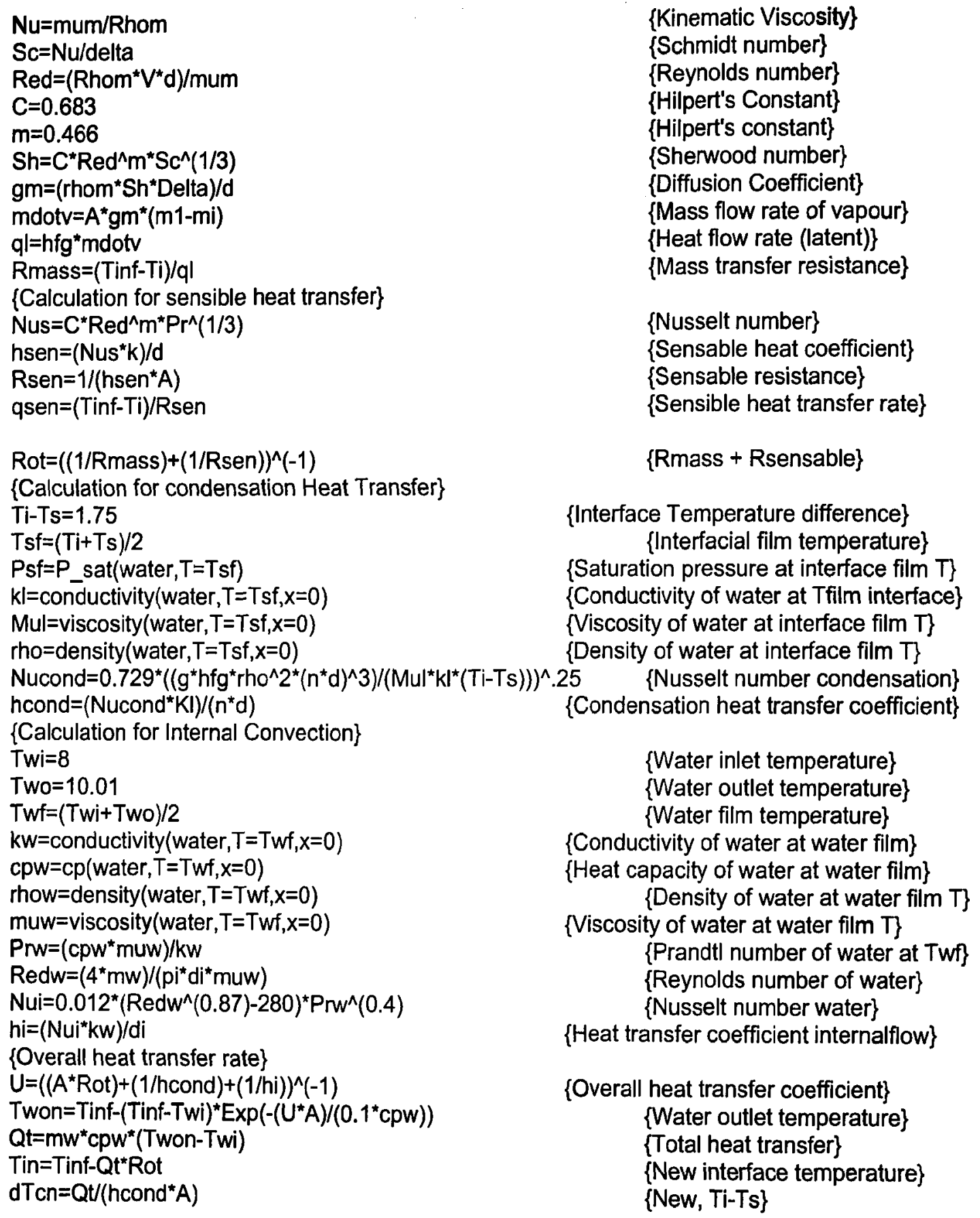


Results for Fourth Coil

Unit Settings

$[\mathrm{J}] /[\mathrm{C}] /[\mathrm{Pa}] /[\mathrm{kg}] /[$ degree $]$

\begin{tabular}{|c|c|c|}
\hline \multicolumn{3}{|r|}{ Phiav $=1.072$} \\
\hline$C=0.683$ & & Phiva $=0.924$ \\
\hline$c p=1007$ & & $P r=0.7268$ \\
\hline $\mathrm{cpw}=4190$ & & Prw $=9.965$ \\
\hline$d=0.01$ & & Psf $=1368$ \\
\hline Delta $=0.00002733$ & & $\mathrm{Pv}=17930$ \\
\hline $\mathrm{DH} 2 \mathrm{Oa}=0.000026$ & & Pv1=14929 \\
\hline $\mathrm{di}=0.007$ & & $P v f=5663$ \\
\hline $\mathrm{dTcn}=1.74$ & & $P v i=1450$ \\
\hline $\mathrm{g}=9.81$ & & $Q$ flow $=0.13$ \\
\hline $\mathrm{gm}=0.05963$ & & $\mathrm{ql}=703$ \\
\hline hcond $=8967$ & & $\mathrm{qsen}=132.8$ \\
\hline$h f g=2.471 E+06$ & $i$ & $Q t=836$ \\
\hline $\mathrm{Hg}=52455$ & & $\mathrm{R}=8314$ \\
\hline $\mathrm{hi}=8868$ & & Red $=1946$ \\
\hline hsen $=54.99$ & & Redw $=13524$ \\
\hline $\mathrm{Hv}=2.523 \mathrm{E}+06$ & & $\mathrm{Rh}=0.8326$ \\
\hline $\mathrm{k}=0.02626$ & & rho $=999.5$ \\
\hline $\mathrm{kl}=0.5705$ & & Rhoal $=0.8962$ \\
\hline$k w=0.5655$ & & Rhoai=1.203 \\
\hline $\mathrm{L}=1.7$ & & Rhom=1.104 \\
\hline $\mathrm{m}=0.466$ & & Rhov1 $=0.09781$ \\
\hline $\mathrm{m} 1=0.0984$ & & Rhovi $=0.011$ \\
\hline $\mathrm{Ma}=28.97$ & & rhow $=1000$ \\
\hline mdotv $=0.0002845$ & & Rmass $=0.06434$ \\
\hline $\mathrm{mi}=0.009065$ & & Rot $=0.054$ \\
\hline $\mathrm{mua}=0.00001896$ & & Rsen $=0.3405$ \\
\hline $\mathrm{Mul}=0.001248$ & & $\mathrm{Sc}=0.6108$ \\
\hline $\mathrm{mum}=0.00001843$ & & $\mathrm{Sh}=19.76$ \\
\hline $\mathrm{muv}=0.00001016$ & & $\mathrm{Tf}=35.11$ \\
\hline muw $=0.001345$ & & $\mathrm{Ti}=12.5$ \\
\hline $\mathrm{Mv}=18.02$ & & $\mathrm{Tin}=12.5$ \\
\hline $\mathrm{mw}=0.1$ & & $\operatorname{Tinf}=57.7$ \\
\hline$n=9$ & & $\mathrm{Ts}=10.75$ \\
\hline $\mathrm{Nu}=0.0000167$ & & $\mathrm{Tsf}=11.63$ \\
\hline Nucond $=1414$ & & $\mathrm{Twf}=9.005$ \\
\hline Nui $=109.8$ & & Twi $=8$ \\
\hline Nus $=20.94$ & & Two $=10.01$ \\
\hline $\mathrm{Pal}=85071$ & & Twon=9.99 \\
\hline Paf $=94337$ & & $\mathrm{U}=321.1$ \\
\hline $\mathrm{Pai}=98550$ & & $\mathrm{~V}=3.25$ \\
\hline
\end{tabular}




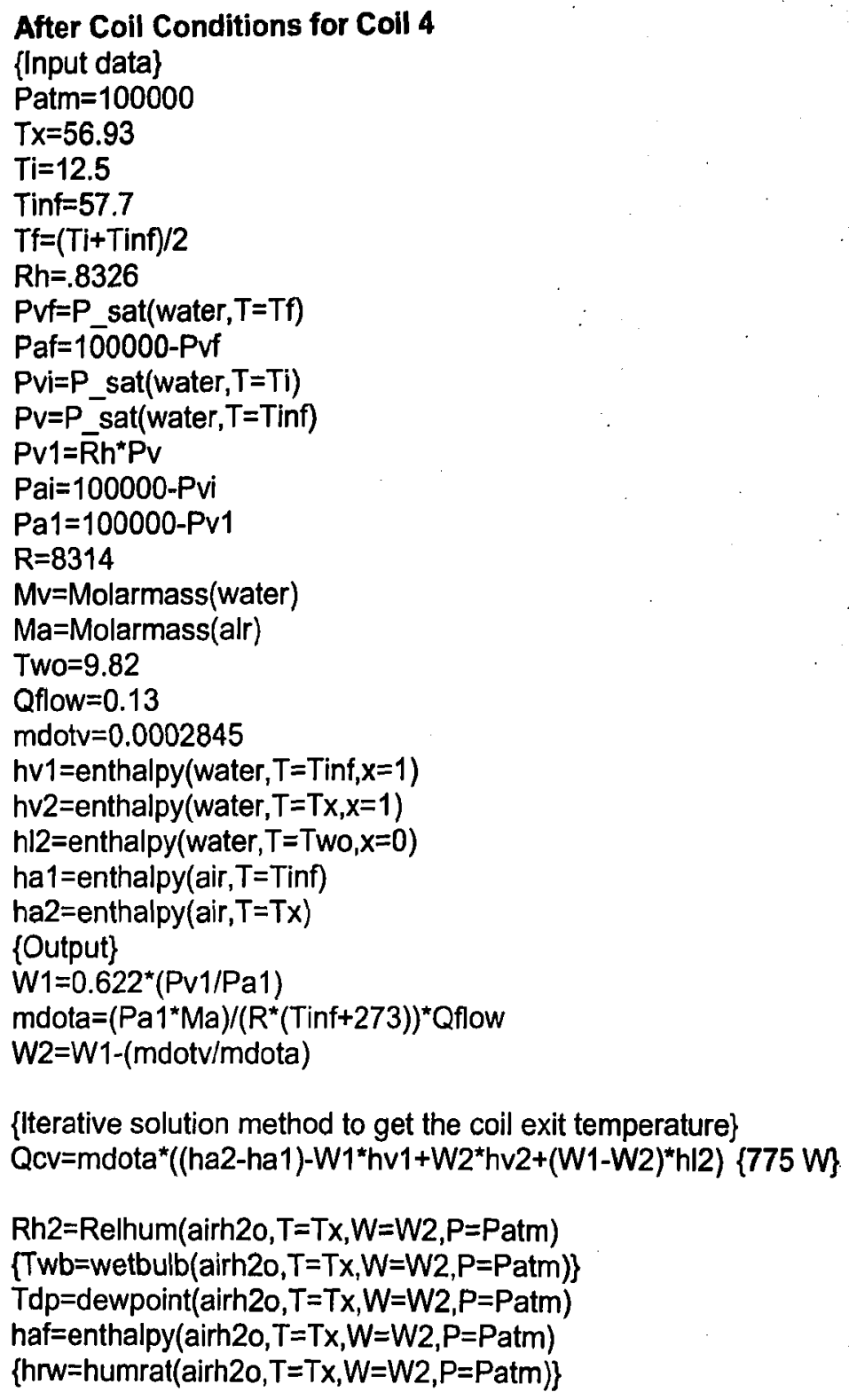




\author{
Results after Coil Conditions for Coil 4 \\ hal $=331492$ \\ ha2 $=330716$ \\ haf $=334648$ \\ $\mathrm{hl} 2=41234$ \\ $\mathrm{hvl}=2.605 \mathrm{E}+06$ \\ hv2 $=2.603 \mathrm{E}+06$ \\ $\mathrm{Ma}=28.97$ \\ mdota $=0.117$ \\ mdotv $=0.0002845$ \\ $\mathrm{Mv}=18.02$ \\ $\mathrm{Pa} 1=85092$ \\ Paf $=94342$ \\ $\mathrm{Pai}=98550$ \\ Patm $=100000$ \\ $\mathrm{Pv}=17905$ \\ Pv1 $=14908$ \\ $\mathrm{Pvf}=5658$ \\ $\mathrm{Pvi}=1450$ \\ Qceve 836 \\ Qflow $=0.13$ \\ $\mathrm{R}=8314$ \\ $\mathrm{Rh}=0.8326$ \\ Rh $2=0.8436$ \\ $\mathrm{Tdp}=53.44$ \\ $\mathrm{Tf}=35.1$ \\ $\mathrm{Ti}=12.5$ \\ Tinf $=57.7$ \\ Two $=9.82$ \\ Txe 603 \\ $\mathrm{W} 1=0.1090$ \\ $\mathrm{W} 2=0.1065$
}




\section{Appendix C - Tables}

Table: Constants of Equation for circular cylinder in cross flow [12]

\begin{tabular}{ccc}
\hline $\boldsymbol{R} \boldsymbol{e}_{\boldsymbol{D}}$ & $\boldsymbol{C}$ & $\boldsymbol{m}$ \\
\hline $0.4-4$ & 0.989 & 0.330 \\
$4-40$ & 0.911 & 0.385 \\
$40-4000$ & 0.683 & 0.466 \\
$4000-40,000$ & 0.193 & 0.618 \\
$40,000-400,000$ & 0.027 & 0.805
\end{tabular}




\section{REFERENCES}

[1] Jia, L., Peng, X.F., Sun, J.D., and Chen, T.B., An Experimental Study on Vapour Condensation of Wet Flue Gas in a Plastic Heat Exchanger, Heat TransferAsian Research, 30 (7), (2001)

[2] Engineering Equation Solver, F-Chart, Software, Box 44042, Madison, Wisconsin U.S.A., (2005)

[3] Fundamentals, American Society of Heating, Refrigeration and Air-Conditioning Engineers Inc., N.E., Atlanta, GA. pp. 5.2, (1989)

[4] Rose, J., W., Approximate Equations for Forced Convection Condensation in the Presence of Non-Condensing Gas on a Flat Plate and Horizontal Tube, Int. J. Heat and Mass Transfer 23, pp. 539-546, (1980)

[5] Sparrow, E., M., Minkowycz, W., J., and Saddy, M., Forced Convection Condensation in the Presence of Noncondensable and Interfacial Resistance, Int. J. Heat and Mass Transfer 10, pp. 1845-1892, (1967)

[6] Mills, A., F., Tan, C., and Chung, D., K., Experimental Study of Condensation from Steam -air Mixtures Flowing over a Horizontal Tube: overall condensation rates in proc. $5^{\text {th }}$ Int. Heat Transfer Conference (Tokyo), Vol. 5 paper CT 1.5, pp. 20$30,(1974)$

[7] Fujii, T., Uehara, H, and Kurato, C., Laminar Film wise condensation of a flowing vapour on a horizontal cylinder,. Int. Heat and Mass Transfer 15, pp. 235-246, (1972) 
[8] Colburn, A. P. and T. B. Drew, "The Condensation of Mixed Vapors,"

Transactions of the AICHE Vol. 33 (1) pp. 197-215, (1937)

[9] Colburn, A., P., Hougen, O., A., Design of Cooler Condenser for Mixtures of Vapors with Non-condensing Gases, Ind. Eng. Chem., 26, pp. 1178-1182 (1934)

[10] Terekhov, V., I., Terekhov, V., V., Sharov, K., A., Heat and Mass Transfer in Condensation of Water Vapour from Moist Air, Journal of Engineering Physics and Thermophysics, Vol. 71 No. 5, pp. 1473-1481, (1998)

[11] Naylor, D., Oosthuizen, P., H., Energy Recovery from an Industrial Clothes Dryer Using a Condensing Heat Exchanger, Heat Transfer Calculation, McGraw Hill New York, p.28.1, (2005)

[12] Incropera, Frank P., Dewitt, David P., External Forced Convection, Fundamentals of Heat and Mass Transfer John Wiley\& Sons, pp. 347-396, (1996)

[13] Wilke, R., C., A viscosity Equation for Gas Mixtures, J. Chem. Phys. 18, pp 517-519, (1950)

[14] Oosthuizen, P., H., David, N. "Condensation," Introduction to Convective Heat Transfer Analysis, McGraw Hill, Series in Mechanical Engineering, (1999)

[15] Rohsenow, W., M., Hartnett, J., P., and Cho, Y., I., Hand Book of Heat Transfer $3^{\text {rd }}$ Edition, McGraw Hill New York, (1998)

[16] Hagen, K., D., External Forced Convection, Heat Transfer with Applications Prentice Hall, New Jersey, pp 271-281, (1999)

[17] Naylor D., Private Communications (2005) 